\title{
Water-Cooled Thermoelectric Generators for Improved Net Output Power: A Review
}

\author{
Björn Pfeiffelmann ${ }^{1}$, Ali Cemal Benim ${ }^{1, *(1)}$ and Franz Joos ${ }^{2}$ \\ 1 Center of Flow Simulation, Faculty of Mechanical and Process Engineering, Düsseldorf University of \\ Applied Sciences, D-40476 Düsseldorf, Germany; bjoern.pfeiffelmann@hs-duesseldorf.de \\ 2 Laboratory of Turbomachinery, Faculty of Mechanical Engineering, Helmut Schmidt University, \\ D-22043 Hamburg, Germany; joos@hsu-hh.de \\ * Correspondence: alicemal.benim@hs-duesseldorf.de or alicemal@prof-benim.com
}

Citation: Pfeiffelmann, B.; Benim,

A.C.; Joos, F. Water-Cooled

Thermoelectric Generators for Improved Net Output Power: A Review. Energies 2021, 14, 8329. https://doi.org/10.3390/en14248329

Academic Editors: Amir Pakdel and David Berthebaud

Received: 8 November 2021

Accepted: 8 December 2021

Published: 10 December 2021

Publisher's Note: MDPI stays neutral with regard to jurisdictional claims in published maps and institutional affiliations.

Copyright: (c) 2021 by the authors. Licensee MDPI, Basel, Switzerland. This article is an open access article distributed under the terms and conditions of the Creative Commons Attribution (CC BY) license (https:/ / creativecommons.org/licenses/by/ $4.0 /)$.

\begin{abstract}
Thermoelectric generators (TEGs) have the ability to convert waste heat into electrical energy under unfavorable conditions and are becoming increasingly popular in academia, but have not yet achieved a broad commercial success, due to the still comparably low efficiency. To increase the efficiency and economic viability of TEGs, research is performed on the materials on one hand and on the system connection on the other. In the latter case, the net output power of the cooling system plays a key role. At first glance, passive cooling seems preferable to active cooling because it does not affect the net electrical output power. However, as shown in the present review, the active cooling is to be preferred for net output power. The situation is similar in air and water-cooling. Even though air-cooling is easier to set up, the water-cooling should be preferred to achieve higher net output power. It is shown that microchannel cooling has similar hydraulic performance to conventional cooling and inserts increase the net output power of TEG. As the review reveals that active water-cooling should be the method of choice to achieve high net output power, it also shows that a careful optimization is necessary to exploit the potential.
\end{abstract}

Keywords: forced convection; heat transfer; net output power; thermoelectric generator; water-cooling

\section{Introduction}

There has been a noticeable revival of thermoelectric Generators (TEGs) in the last decades, although the thermoelectric effects are known nearly for two centuries. This recent increase of TEG applications is in parallel with the increasing will of the nations to reduce greenhouse gas emissions to reach the $2{ }^{\circ} \mathrm{C}$ target, and thereby limit the global warming. On the other hand, the energy demand of humankind is increasing due to economic development. In order to achieve the previously mentioned goal, this must additionally be covered by renewable energies. Detached from this, there is a shortage of resources for fossil fuels and increasing fuel costs are expectable. For both reasons, global warming and resource shortage, it is worth recovering waste heat, or, additionally, converting heat provided by renewables to electricity. One promising option is electrical power generation using TEG. With a temperature gradient applied, a TEG converts heat into electricity directly, without moving parts.

An important evaluation criterion for heat recovery systems is efficiency, which in the case of TEG depends on the used thermoelectric material combination. As Altenkirch between 1909 and 1911 showed, there are materials especially convenient for TEG applications, which have a high Seebeck coefficient with low thermal conductivity to hold the temperature gradient and a low electrical resistance to diminish Joule heating [1]. Bismuth telluride semiconductor compounds are still the state of the art at commercial available TEGs, since they are fulfilling these criteria well. Although the thermoelectric material research is making progress [2-4], the conversion efficiency is still around 5\%. Apart from efficiency, the limiting factor in many applications is on the one hand the maximum 
temperature under which the TEG can be operated. The maximum temperature is, for commercially available and economically justifiable TEGs, in the range from $200{ }^{\circ} \mathrm{C}$ to $330^{\circ} \mathrm{C}$. On the other hand, research is being conducted for developing environmentally friendly and inexpensive materials to compensate the low efficiency with the latter.

As already highlighted, a promising field of application for TEG, but not the only one, is waste heat recovery. Here, efficiency is not the only objective. Other objectives that can be well fulfilled by a TEG are portability, low maintenance effort, low control effort, silent operation, small size, reliability, retrofittability, scalability ( $\mu W-\mathrm{kW})$, high safety. Areas of application for TEG where waste heat is present include exhaust gas of automobile, stoves, gasifiers, boilers, industrial processes, fuel cells, photovoltaic cells, central processing units (CPUs) or humans [5]. In the worst case, in all these applications, heat is released unused to the environment at a low temperature level, often fluctuating. TEGs are able to use this heat source and provide it again in electrical form, even with strong fluctuations.

For some of the mentioned applications, cycle processes such as the Organic Rankine Cycle (ORC), Sterling Engine or steam turbines are also suitable. These have a somewhat higher efficiency, but lack many of the previously mentioned advantages of the TEG, such as freedom from maintenance.

In addition to waste heat utilization, the aforementioned properties are also indispensable in applications in which highly portable electrical power supply by primary energy is required, which is why TEGs have already proven themselves in space, military, medical applications and off-grid power (domestic, sensors).

To improve the dissemination and applicability of TEG in waste heat recovery, two paths can be taken. First, as previously described, thermoelectric materials and thus the efficiency of TEG can be increased. Secondly, the thermal system configuration can be improved, which plays a decisive role. One of the important components here is cooling, which can be categorized into active and passive cooling (Figure 1). At first glance, passive cooling [6-11] is preferable because it does not affect the electrical net output power. However, since the yield depends directly on the temperature difference, the relatively high thermal resistance of passive cooling has a negative effect on the yield. Active cooling can significantly increase the temperature difference. Nevertheless, this can have a reducing influence on the net electrical output power, since a pressure difference must be built up for active cooling, which in turn consumes electrical power in most cases. At second glance, the net output power can be increased, because in many cases the temperature difference has a stronger positive influence on the net output power, compared to the negative influence of the active cooling. This should be carefully balanced when designing the thermal system of a TEG and this is the main investigation of this review. Obviously, passive cooling offers other advantages over active cooling, such as lower investment costs or higher compactness.

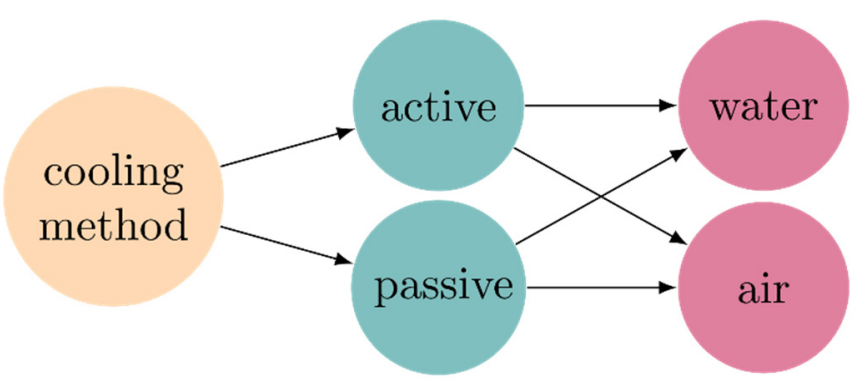

Figure 1. Classification of TEG system cooling.

TEG systems have already been investigated in various reviews with different focus. Two reviews focus on the design of TEG test rigs [12] and on medical applications of TEG [13]. In the field of solar energy, the reviews focus on solar thermal application of TEG [14,15], on TEG solar ponds [16] or on the combination of TEG and photovoltaic 
system [17]. Several very detailed reviews firstly discuss the progress of the material development of TEG and then conclude with application cases from different fields $[2,4,5,18,19]$.

In the above-mentioned reviews, the output power was discussed without considering the power necessary for the cooling. This means that it was not possible to evaluate the net output power, which is actually the most important parameter for an engineering application. The net output power was only marginally discussed in the reviews of Elghool et al. [3] and Sajid et al. [20], which, from this perspective, have a certain similarity with the present review. However, this aspect, i.e., the net output power is the main focus of the present review, and it is discussed in much more detail. In contrast to the previously mentioned reviews, the present review focuses exclusively on active water-cooling and the associated net output power in order to provide a decision-making aid for the design of water-cooled TEG systems.

\section{The Influence of Cooling on the TEG Performance}

The purpose of this chapter is to describe the relationships between the potential power of a TEG and the cooling that affects it. A simplified model is described to illustrate this relationship. In this model, it is assumed that the temperature distributions on the hot side and the cold side are uniform and that the heat and current flow are approximated to have a one-dimensional behaviour. In contrast to this simple model, a commercially available TEG consists out of several ten to several hundred thermocouples to achieve a feasible current and/or voltage. The typical Bismuth Telluride $\left(\mathrm{Bi}_{2} \mathrm{Te}_{3}\right)$ couple consist out of $\mathrm{p}$ - and n-type doped semiconductor legs. The following equations describe a single thermocouple with a load resistance applied, but it can be easily extended to multiple number of couples, which is closer to a commercially available TEG. The electrical power provided by a TEG $\mathrm{P}_{0}$ can be determined by [21]:

$$
\mathrm{P}_{0}=\mathrm{I}^{2} \mathrm{R}_{0}
$$

where $R_{0}$ is the electric load resistance, i.e., the resistance externally applied to the TEG, and $I$ is the current flowing through it:

$$
\mathrm{I}=\frac{\alpha\left(\mathrm{T}_{\mathrm{H}}-\mathrm{T}_{\mathrm{C}}\right)}{\mathrm{R}+\mathrm{R}_{0}},
$$

with $\mathrm{T}_{\mathrm{H}}$ and $\mathrm{T}_{\mathrm{C}}$, standing for the temperatures of the hot side and cold side, respectively. The variables $\alpha$ and $R$ in Equation (2) denote the Seebeck coefficient and the electric resistance of the thermocouple, respectively, which are defined as:

$$
\begin{gathered}
\alpha=\left|\alpha_{\mathrm{n}}\right|+\left|\alpha_{\mathrm{p}}\right|, \\
\mathrm{R}=\frac{1_{\mathrm{n}}}{\mathrm{A}_{\mathrm{n}} \sigma_{\mathrm{n}}}+\frac{1_{\mathrm{p}}}{\mathrm{A}_{\mathrm{p}} \sigma_{\mathrm{p}}},
\end{gathered}
$$

In the above equation $1, A, \sigma$ are the length, the cross sectional area and the electric conductivity for each p-type and n-type leg, respectively (indicated by the subscripts $p$ and $\mathrm{n})$. To determine the efficiency $\eta$ of the TEG, the electrical power output is divided by the heat flow rate $\dot{\mathrm{Q}}_{\mathrm{H}}$ on the hot side of the TEG:

$$
\begin{gathered}
\eta=\frac{\mathrm{P}_{0}}{\dot{\mathrm{Q}}_{\mathrm{H}}}, \\
\dot{\mathrm{Q}}_{\mathrm{H}}=\mathrm{K}\left(\mathrm{T}_{\mathrm{H}}-\mathrm{T}_{\mathrm{C}}\right)+\alpha \mathrm{T}_{\mathrm{H}} \mathrm{I}-\frac{1}{2} \mathrm{I}^{2} \mathrm{R},
\end{gathered}
$$


with the thermal conductance of the thermocouple $\mathrm{K}$ depending on the thermal conductivity $\lambda$ of the TEG legs through

$$
\mathrm{K}=\lambda_{\mathrm{n}} \frac{\mathrm{A}_{\mathrm{n}}}{\mathrm{l}_{\mathrm{n}}}+\lambda_{\mathrm{p}} \frac{\mathrm{A}_{\mathrm{p}}}{\mathrm{l}_{\mathrm{p}}} .
$$

To achieve the maximum electric power output of a TEG, it can be shown that the load resistance $R_{0}$ needs to be the same as the electric resistance of the couple $R$ [21].

The cooling of the TEG is connected to the electrical power output by the cold side temperature $\mathrm{T}_{\mathrm{C}}$. If $\mathrm{T}_{\mathrm{C}}$ decreases, the current, the electrical power and the heat flow increases. In this review the focus is on active water cooling and therefore the cold side temperature depends on the heat transfer coefficient:

$$
\dot{\mathrm{Q}}_{\mathrm{C}}=\mathrm{h}\left(\mathrm{A}_{\mathrm{n}}+\mathrm{A}_{\mathrm{p}}\right)\left(\mathrm{T}_{\mathrm{C}}-\mathrm{T}_{\mathrm{W}}\right),
$$

where $h$ is the heat transfer coefficient, $T_{W}$ the average water temperature in the water channel and $\dot{Q}_{C}$ is the heat flow rate on the cold side:

$$
\dot{\mathrm{Q}}_{\mathrm{C}}=\dot{\mathrm{Q}}_{\mathrm{H}}-\mathrm{P}_{0} \text {. }
$$

The heat transfer coefficient is related to the Nusselt number $(\mathrm{Nu})$ as follows:

$$
\mathrm{h}=\frac{\mathrm{Nu} \lambda_{\mathrm{W}}}{\mathrm{D}_{\mathrm{h}}},
$$

with the thermal conductivity of the water $\lambda_{W}$ and the hydraulic diameter $D_{\text {hyd }}$.

In order to achieve a sufficiently high heat transfer coefficient, the pump used has to transport water through the channels, with a certain flow rate. This means, depending on the flow rate $\dot{V}$, a certain pressure difference $\Delta p$ must be overcome. The power required by the pump to fulfil this task, i.e., the hydraulic power $\mathrm{P}_{\text {hyd }}$ is given by:

$$
\mathrm{P}_{\text {hyd }}=\dot{\mathrm{V}} \Delta \mathrm{p} .
$$

For waste heat recovery the hydraulic power is quite often the only effort that has to be invested. In this case, the actual electric power generated, i.e., income minus outcome, is the net output power:

$$
\mathrm{P}_{\text {net }}=\mathrm{P}_{0}-\mathrm{P}_{\text {hyd }} \text {. }
$$

In case of the need for additional power, e.g., electric power to run a hot gas blower, the net output power is further reduced. Within this context, the ratio of the hydraulic power requirement to the net output power is an important parameter, which is denoted by $r$ :

$$
r=\frac{P_{\text {hyd }}}{P_{\text {net }}} .
$$

\section{Existing Cooling Methods}

In this section, a comprehensive review study of the different cooling methods and their influence on the net output power of TEG is presented. The section is therefore divided into, according to the geometry of the cooling, (1) conventional channel, (2) microchannel and minichannel, (3) impingement and (4) inserts.

\subsection{Conventional Channel}

The most widely used geometry for water cooling is the conventional channel, due to its ease of fabrication. Water cooled channel was used in different applications, such as waste heat recovery of an air flow [22,23], of a water flow [24,25], of a hot surface, i.e., a CPU [26-28], of automobile exhaust gas [29-40] and of industrial production [41]. However, it also finds application in the utilization of primary energy such as combustion [42,43], 
geothermal energy [44] and solar energy [45-48]. The publications that use conventional channels to cool TEGs, focusing on net output power, are presented below. According to the application area, they are categorized into (1) low temperature waste heat recovery, and (2) combustion applications.

\subsubsection{Low Temperature Waste Heat Recovery}

Su et al. [49] constructed a test bench with two stripe-shaped cooling units with 4 TEGs mounted, because in their previous numerical study [50] they revealed that the stipe-shaped cooling unit has a good cooling performance compared to plate-shaped and diamond-shaped cooling units. The cooling units with the predicted temperature field are shown in Figure 2. Although the diamond-shaped cooling unit achieves a better cooling performance, strip-shaped cooling units are used in the test bench because of the low complexity of their installation. With the capability of the test bench, they showed that the power loss due to the pressure drop could not be neglected, especially at high flow rates. An optimum flow rate for net output power generation was determined, which improved the net output power by $4.8 \%$. When the two stripes were connected serial or parallel, the parallel connection provided the higher net output power. They measured an even higher influence of the flow direction. The net output power of the counter flow configuration is increased by $12.6 \%$ over the output power of the co-flow configuration.

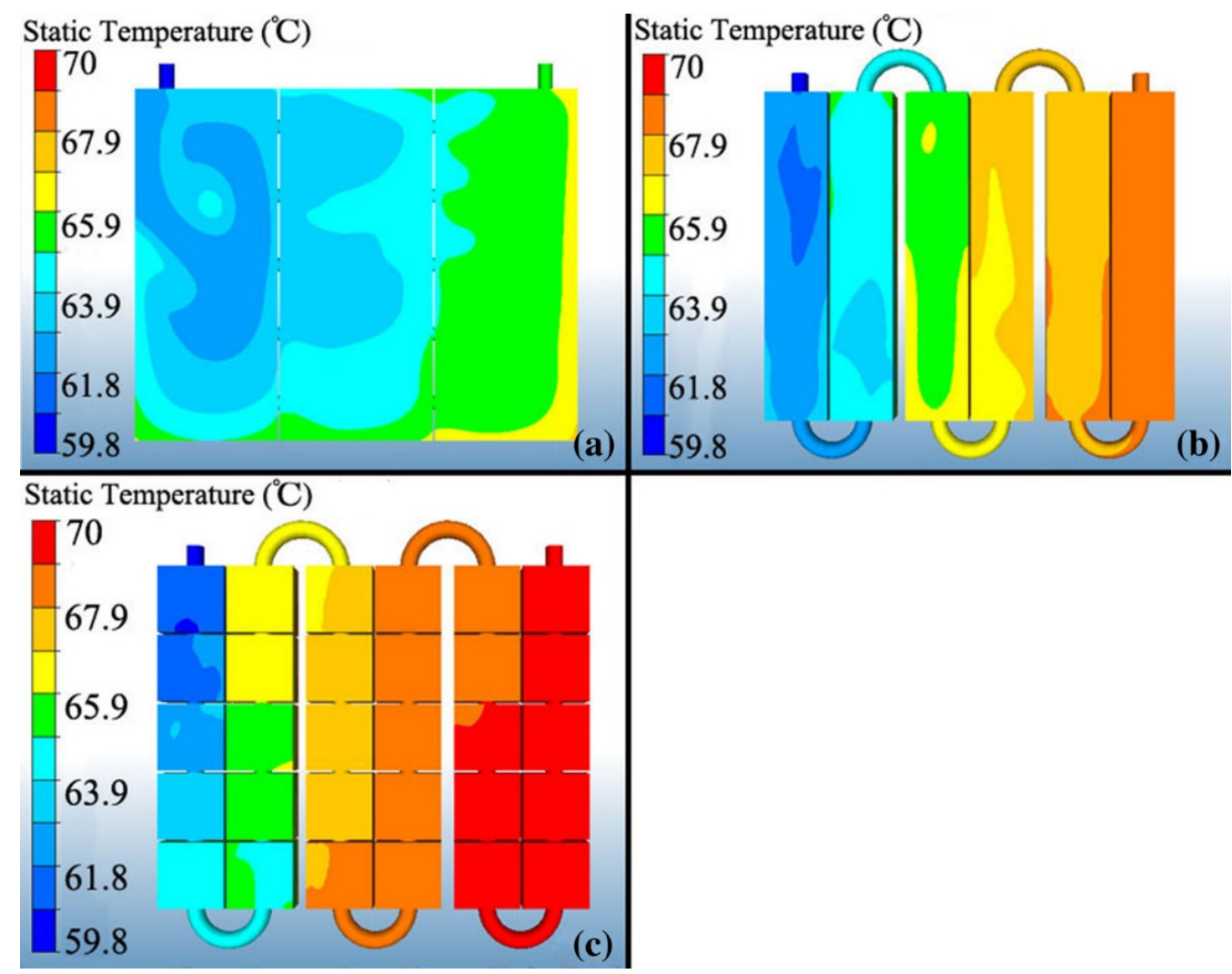

Figure 2. Predicted temperature field of the TEG cooling units: (a) Plate-shaped; (b) Stripe-shaped; (c) Diamond-shaped. Reprint with permission [50]; Copyright 2021, Springer Nature.

Chen et al. [51] came to the same result for the flow direction. They sandwiched forty TEGs between the hot and cold streams of a two-fluid heat exchanger with maximum temperature difference of $80 \mathrm{~K}$ and measured an improvement of $18 \%$ when using a co-flow configuration. In the study, three different fluid heat exchangers were investigated, a block with two tubes, a single channel stripe and a single channel stripe with a lower height and with rougher inner surface (Figure 3). The latter outperformed the others by $7 \%$ in 
terms of power output of the TEG, but the associated increase of pumping power was not documented.

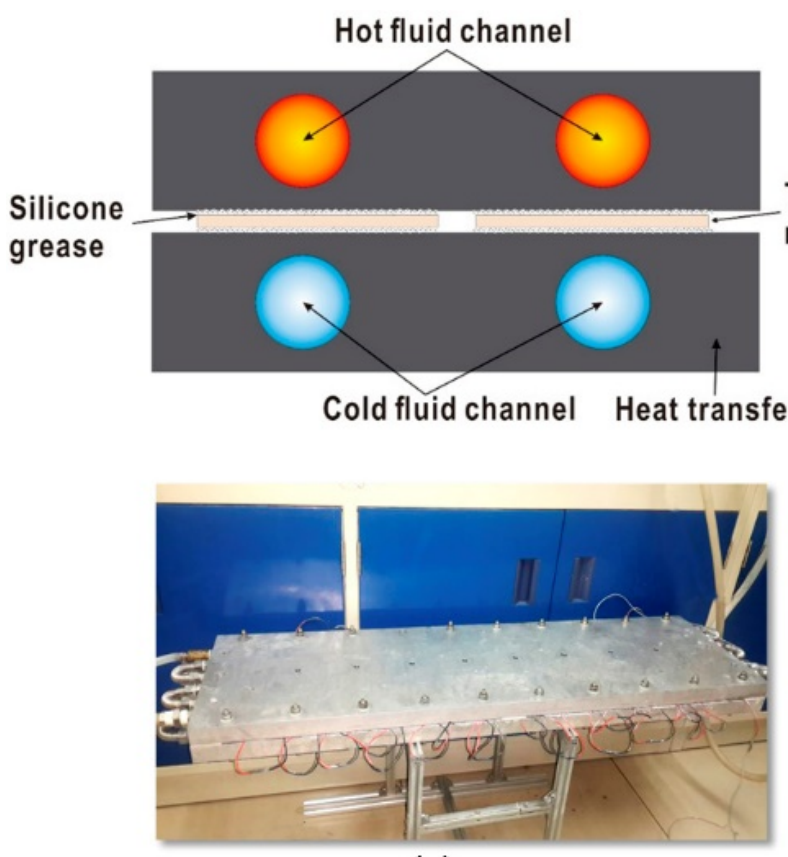

(a)

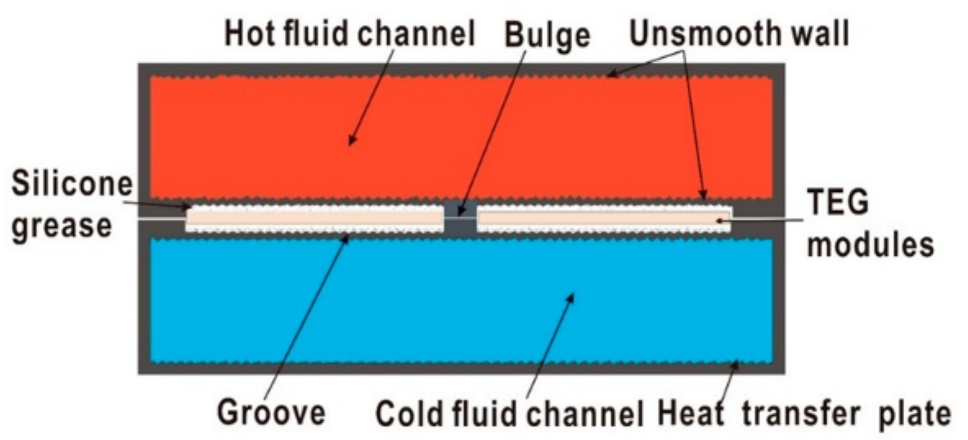

TEG
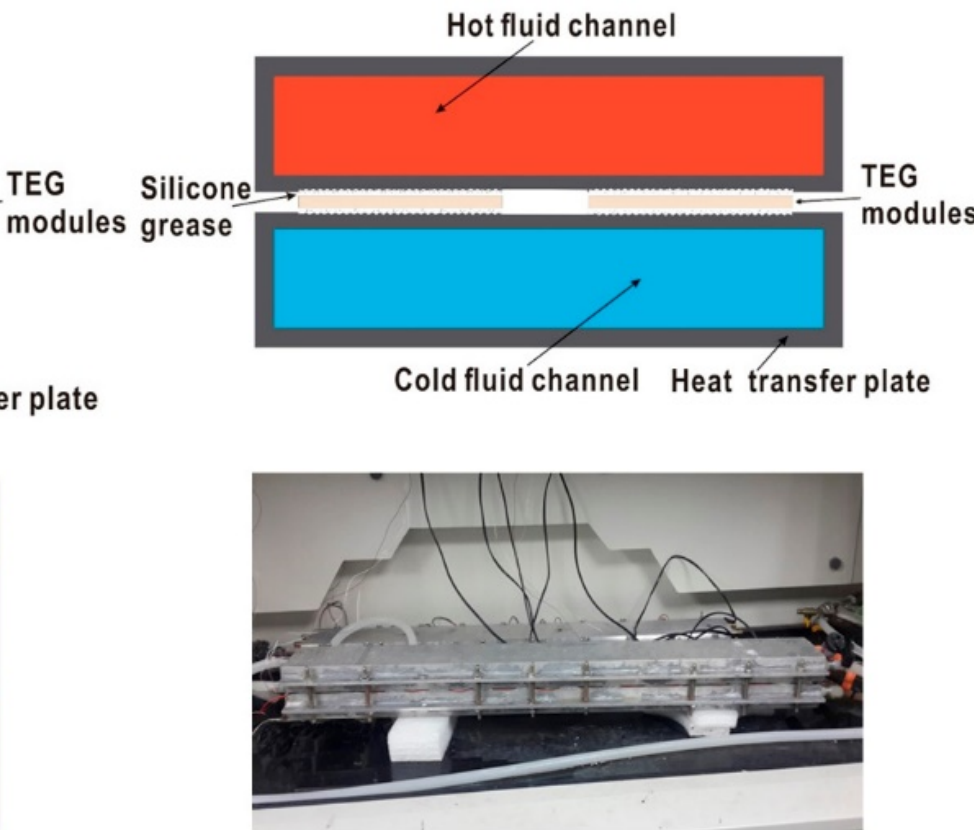

(b)

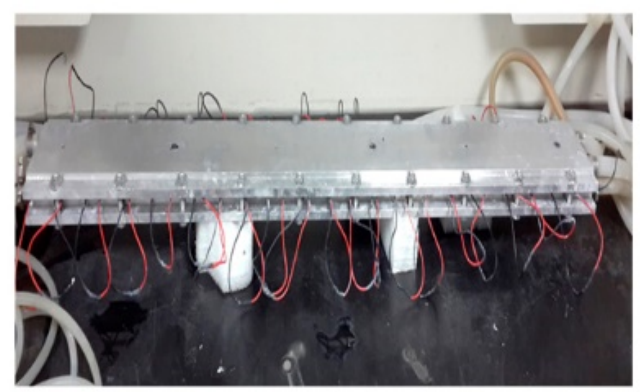

(c)

Figure 3. Different fluid heat exchanger: (a) Block with two tubes; (b) A single channel stripe; (c) A single channel stripe with a lower height and with rougher inner surface [51].

Zhou et al. [52] obtained the opposite result. They numerically found out that the parallel flow ensures higher power generation and higher efficiency compared to the counter flow configuration. The authors modelled and validated the experimental setup of Niu et al. [53,54], which is depicted in Figure 4. In this setup, fifty-six TEG are sandwiched between two hot and three cold fluid heat exchangers, where the direction, in the experimental setup, is a mixture of parallel and cross flow configurations. Here, a temperature dependence of the auxiliary pumping power is measured. The pumping power decreases with increasing fluid temperature. Zhou et al. [52] unified the direction of the flow numerically and predicted a power generation of $33.5 \mathrm{~W}$ and $32.2 \mathrm{~W}$ for parallel and counter flow, respectively. Apart from this, they discovered that by fixing the design space, flow rate and pressure drop, and simultaneously increasing the number of channels, thus the heat exchanger area and the number of TEG lead to a single maximum power point. The output power increased with the increasing heat exchanger area, and compensated the decrease in the Reynolds number and Nusselt number, until the transition regime, where the maximum power point was identified. The output power dropped in the laminar regime, because the 
drop of the Nusselt number could no more be compensated. Therefore, it was concluded by the authors that the optimal flow condition was at the onset of transition regime.

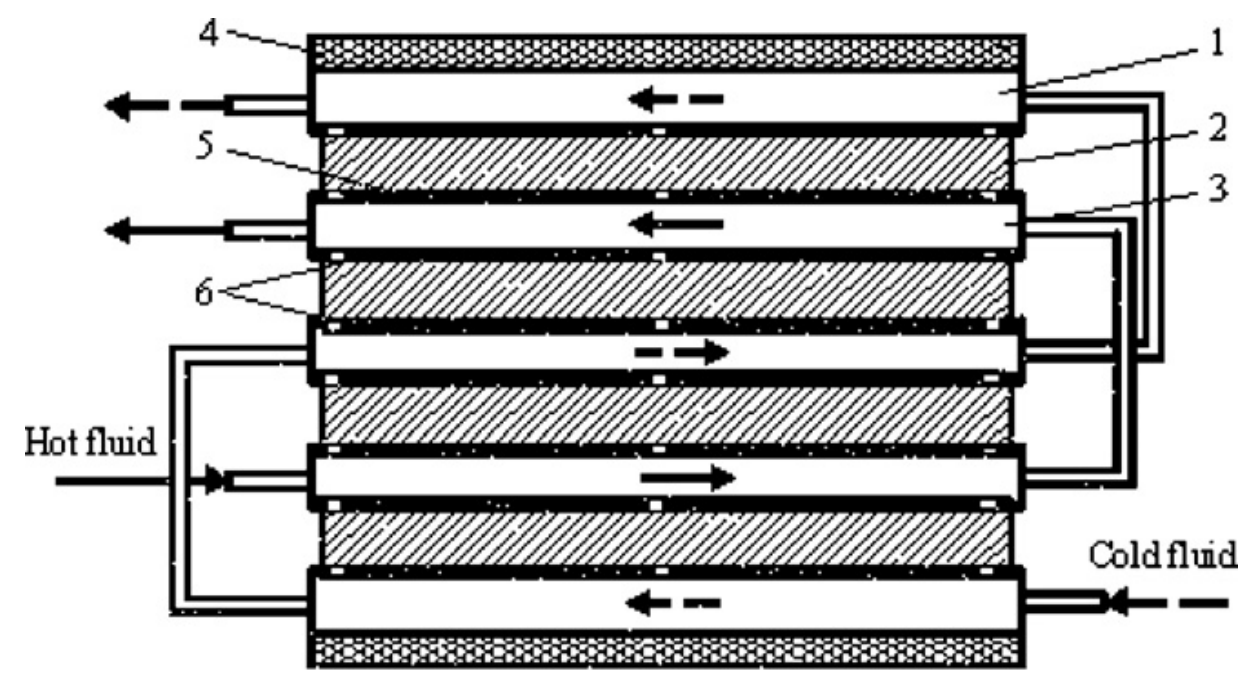

\section{1-Cold fluid passage 2-Themoelectric modıle 3-Hot fluid passage \\ 4 Iinsulation board 5-Thermal grease 6-T-type thermocouple}

Figure 4. Experimental setup of the fluid-fluid TEG heat exchanger of Niu et al. [53]. Reprint with permission [53]; Copyright 2021, Elsevier.

Chen et al. [55] examined the influence of the coolant flow path configuration in a meander structured channel heat exchanger (Figure 5). The heat exchanger cooled a TEG to recover low waste heat, which was originally designed as a thermoelectric cooler (TEC). Repurpose a TEC for waste heat recovery was much cheaper than TEG, but they were limited in the hot side temperature to $150{ }^{\circ} \mathrm{C}$. Different inlet and outlet positions were used, which resulted in perpendicular and parallel coolant flow directions, as depicted in Figure 5. The authors declared this change in the flow path had only a minor influence on the output power of the TEG/TEC.

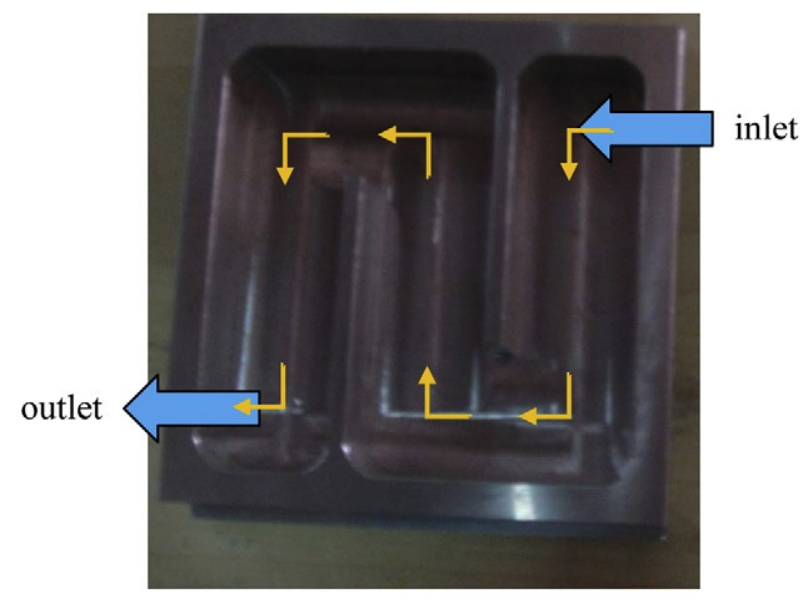

(a)

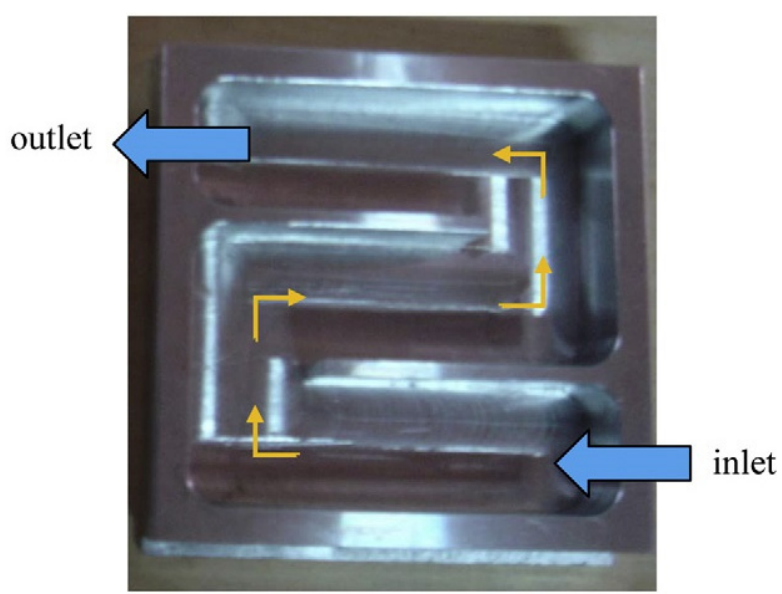

(b)

Figure 5. Meander cooling unit with inflow and outflow: (a) Perpendicular to the channel; (b) Parallel to the channel. Reprint with permission [55]; Copyright 2021, Elsevier.

Lv et al. [56] mathematically modelled and experimentally investigated three types of heat exchanger, finned heat sink (air), heat pipe cooling (air) and water heat exchanger. 
They revealed that the heat pipe cooling produced the best net output power (Figure 6) and the lowest heat exchanger costs of $10.67 \$ \cdot \mathrm{W}^{-1} \cdot \mathrm{K}^{-1}$. It must be noted, that the temperature difference of $50 \mathrm{~K}$ is relatively small. Their result showed a single maximum net output power for two-channel water heat exchanger, while varying the water flow rate.

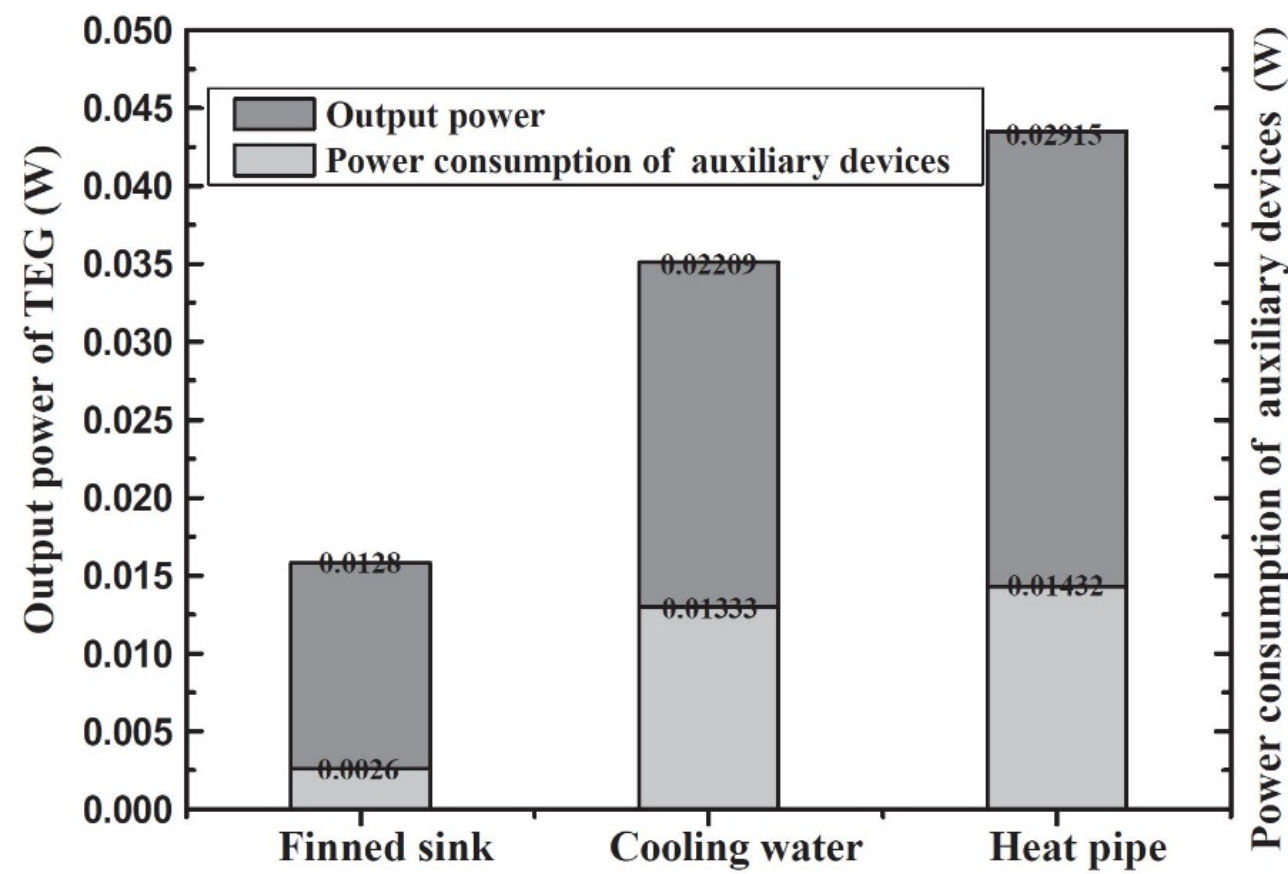

Figure 6. Net output power, output power and power consumption of three different cooling methods. Reprint with permission [56]; Copyright 2021, Elsevier.

The optimization of the maximum output power with the variation of the flow rate was also carried out by Karri et al. [57] and Lei et al. [58] for the automotive application. Karri et al. [57] equipped a coolant heat exchanger, flow channels (six, parallel, rectangular) milled in a block of aluminum, with sixteen TEGs as shown in Figure 7. Fuel savings of about 3\% could be reached with this experimental setup. Lei et al. [58] used a single strip channel to cool eight TEGs and reached a temperature difference between $45 \mathrm{~K}$ and $140 \mathrm{~K}$. This was carried out by combining numerical simulation and experiments. Both reports also discovered a single maximum for the output power, which shifts to larger flow rates as the temperature difference increases. This can be explained by the fact that the heat transfer rate and, thus, the output power are converging to a saturation point as the flow rate is increased, as shown by many authors $[52,59,60]$.

Deng et al. [61] reported the influence of the vehicle speed on the TEG output power cooled with water. A reduction up to $15 \%$ reduction was determined when comparing high and low vehicle speeds from the simulations and experiments. Du et al. [62] numerically compared slow water-cooling $\left(0.012 \mathrm{~m} \cdot \mathrm{s}^{-1}\right)$ with air-cooling with three different vehicle velocities $\left(30,60,100 \mathrm{~km} \cdot \mathrm{h}^{-1}\right)$ as depicted in Figure 8 . Even for the highest velocity of air-cooling, $\left(100 \mathrm{~km} \cdot \mathrm{h}^{-1}\right)$, the net output power was lower compared to the water-cooling, although the output power was higher. The pressure drop and herewith the pumping power was much higher, $4.04 \mathrm{~W}$ (air, $100 \mathrm{~km} \cdot \mathrm{h}^{-1}$ ) compared to $0.005 \mathrm{~W}$ (water). The authors showed that the water-cooling can be further improved with a higher flow rate and baffles in the channel, with a negligible influence on the pumping power. However, they also declared that the design of water cooling is more complicated and extra pumping power is needed to cool down the coolant. 


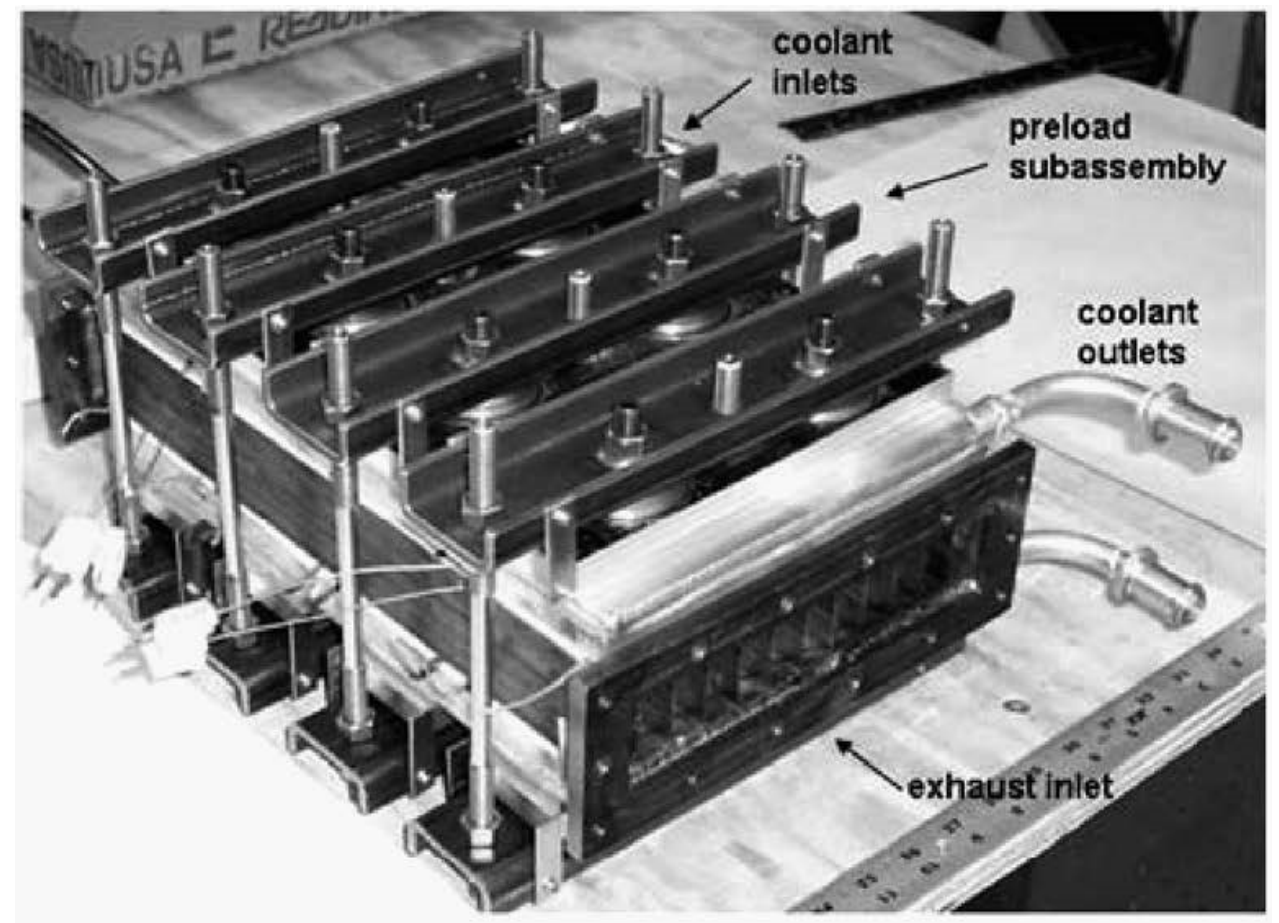

Figure 7. Automotive TEG system with sixteen TEG. Reprint with permission [57]; Copyright 2021, Elsevier.

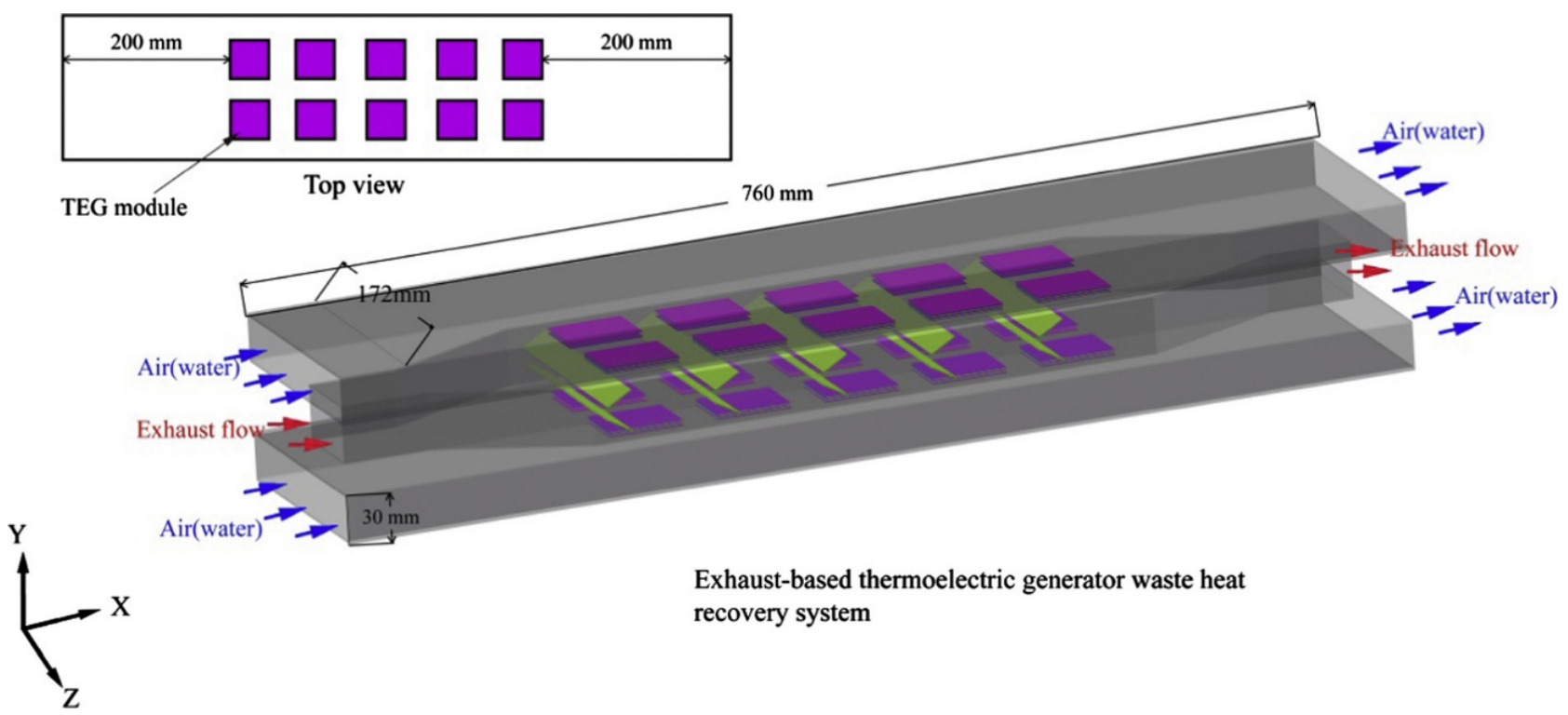

Figure 8. Schematic of the automotive TEG system cooled either by air or by water. Reprint with permission [62]; Copyright 2021, Elsevier.

This extra power need of the fan coil, fan and the pipes in a water cycle is analyzed by Aranguren et al. [63-67]. They numerically and experimentally investigated the whole water cycle of a typical TEG waste heat recovery system, consisting of the cooling block, the pump, the fan coil and the fan. The experimental setup is illustrated in Figure 9. Instead of producing electrical power, the system was consuming electrical power in the worst case, when the water mass flow rate was unnecessary high. Therefore the highest net output power was not obtained at the operating point with the lowest thermal resistance of the cooling system. The system produced the highest power when the fan was off and the water cooling pump was working in an optimal manner. 


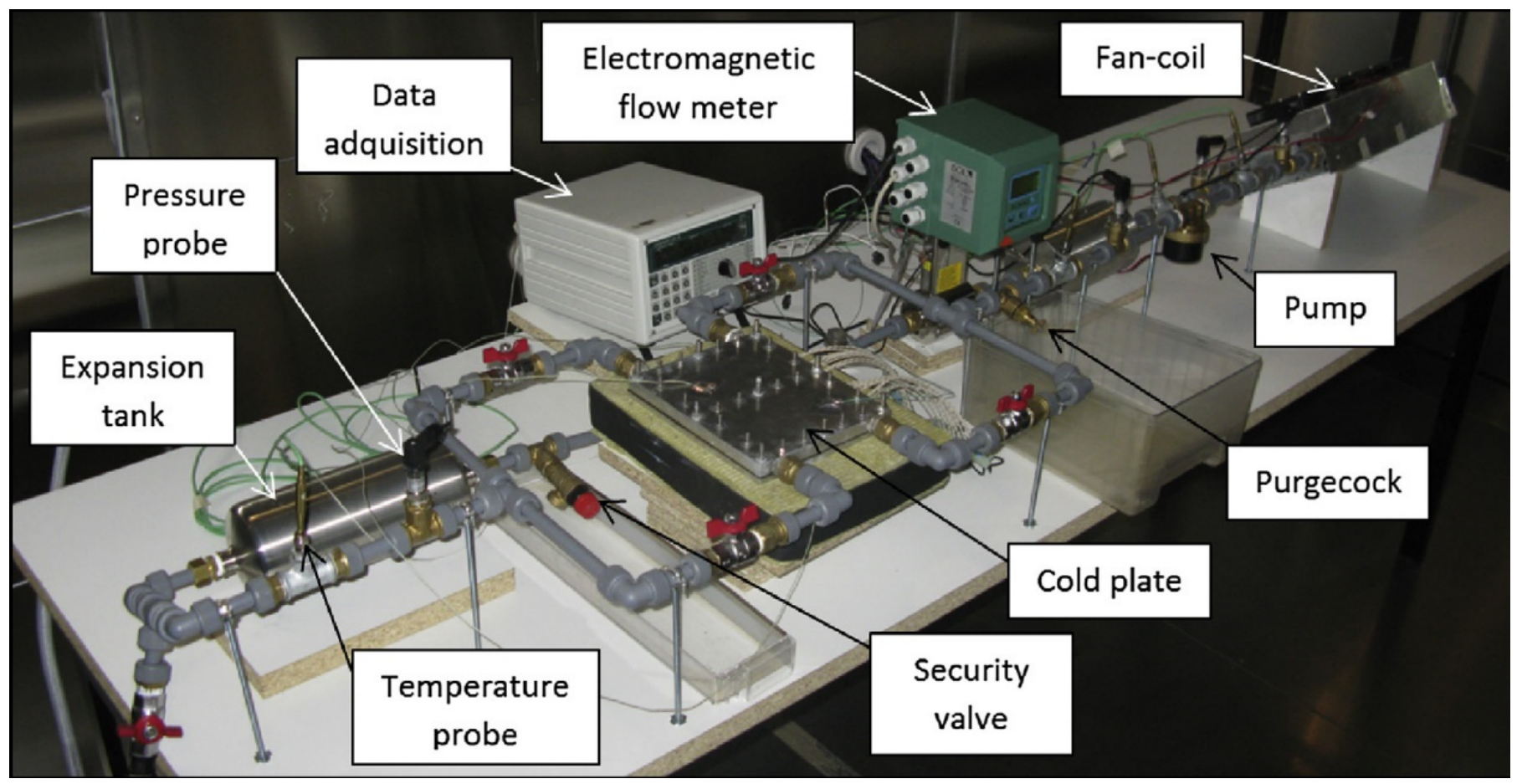

Figure 9. Experimental setup to investigate the consumption of the auxiliary equipment. Reprint with permission [64]; Copyright 2021, Elsevier.

\subsubsection{Combustion}

Montecucco et al. [68] conducted a demonstration of technical feasibility of a combined heat and power system (CHP), a solid-fuel stove (Figure 10). The four TEGs in the test rig provided a thermal power of $600 \mathrm{~W}$ and an electrical power of $27 \mathrm{~W}$. This implied an efficiency of $5 \%$, where, however, the pump consumption of $8 \mathrm{~W}$ was neglected. No optimization was reported, since the author was satisfied with the result, by driving two high-power Universal Serial Bus (USB) devices.

Aravind et al. [69-72] studied intensively the performance of a portable combustion based micro power generator. Hydrocarbon fuels were burned to provide the heat conducted through two TEGs. One part of their study focused on the performance of different heat removal concepts [70]. They used a fin heat exchanger passively cooled with air, cooled actively with a fan, and a block with three channels cooled with water. As shown in Figure 11, the determined that the net output power was $0.3 \mathrm{~W}, 2.5 \mathrm{~W}$ and $4.5 \mathrm{~W}$, respectively. Although the water-cooled system had an auxiliary power consumption of $0.22 \mathrm{~W}$, it provided the highest net output power, because the heat flow through the TEG was $50 \%$ increased by using the water-cooled system compared to air-cooled system. They noticed a negligible influence of the water flow rate on the output power, which could be related to the previously reported reaching of the plateau. 


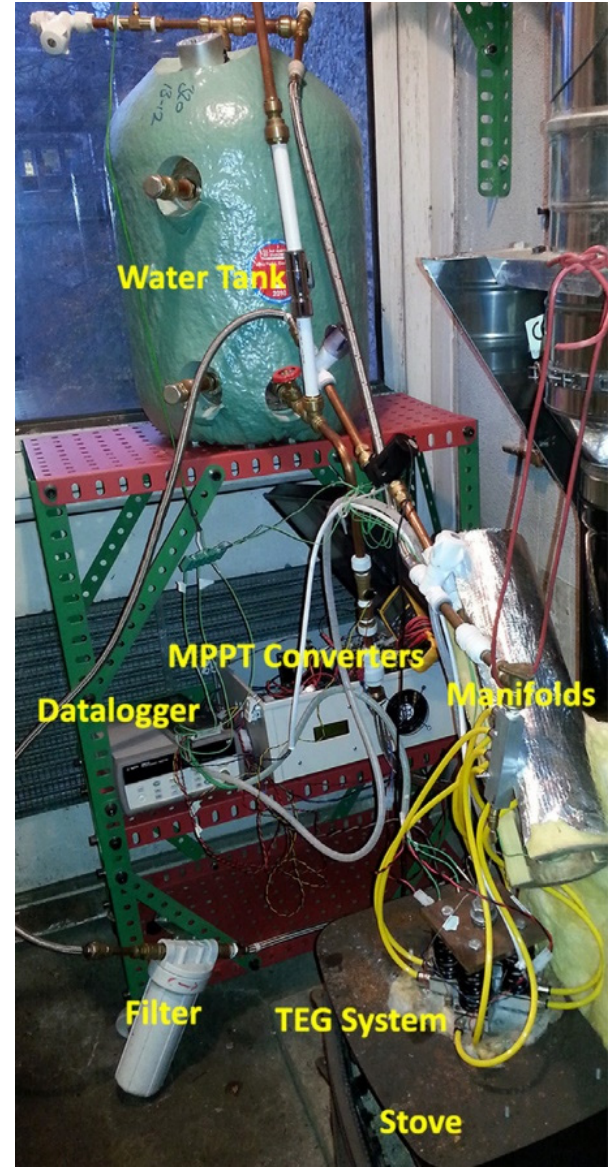

(a)
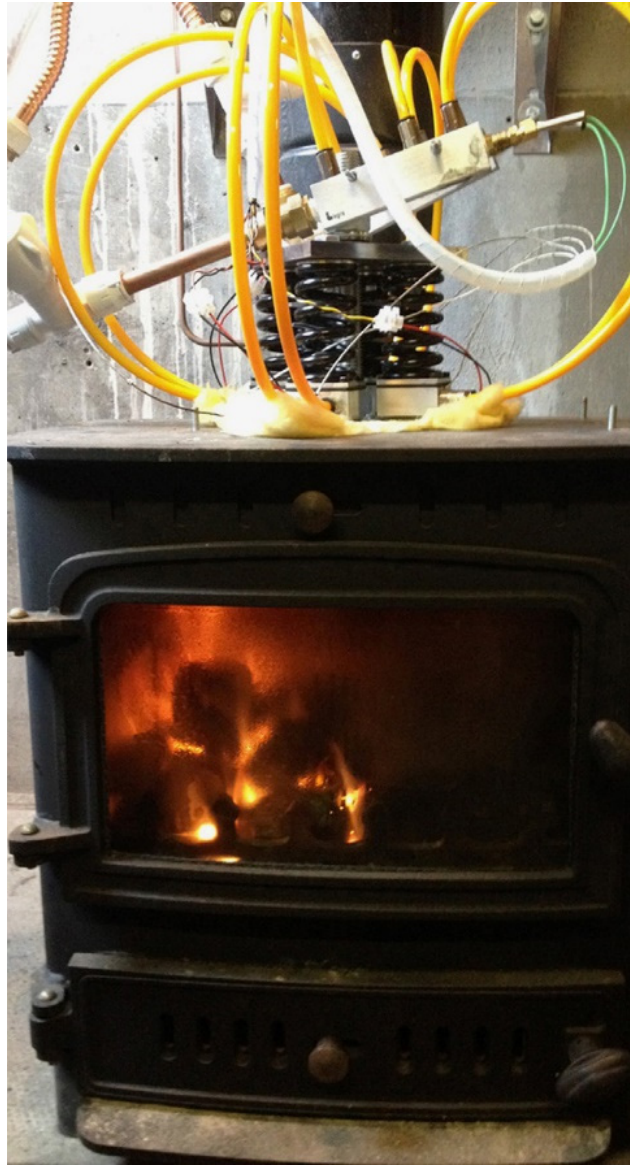

(b)

Figure 10. Experimental stove TEG system: (a) Complete CHP system; (b) Close-up image of the stove. Reprint with permission [68]; Copyright 2021, Elsevier.

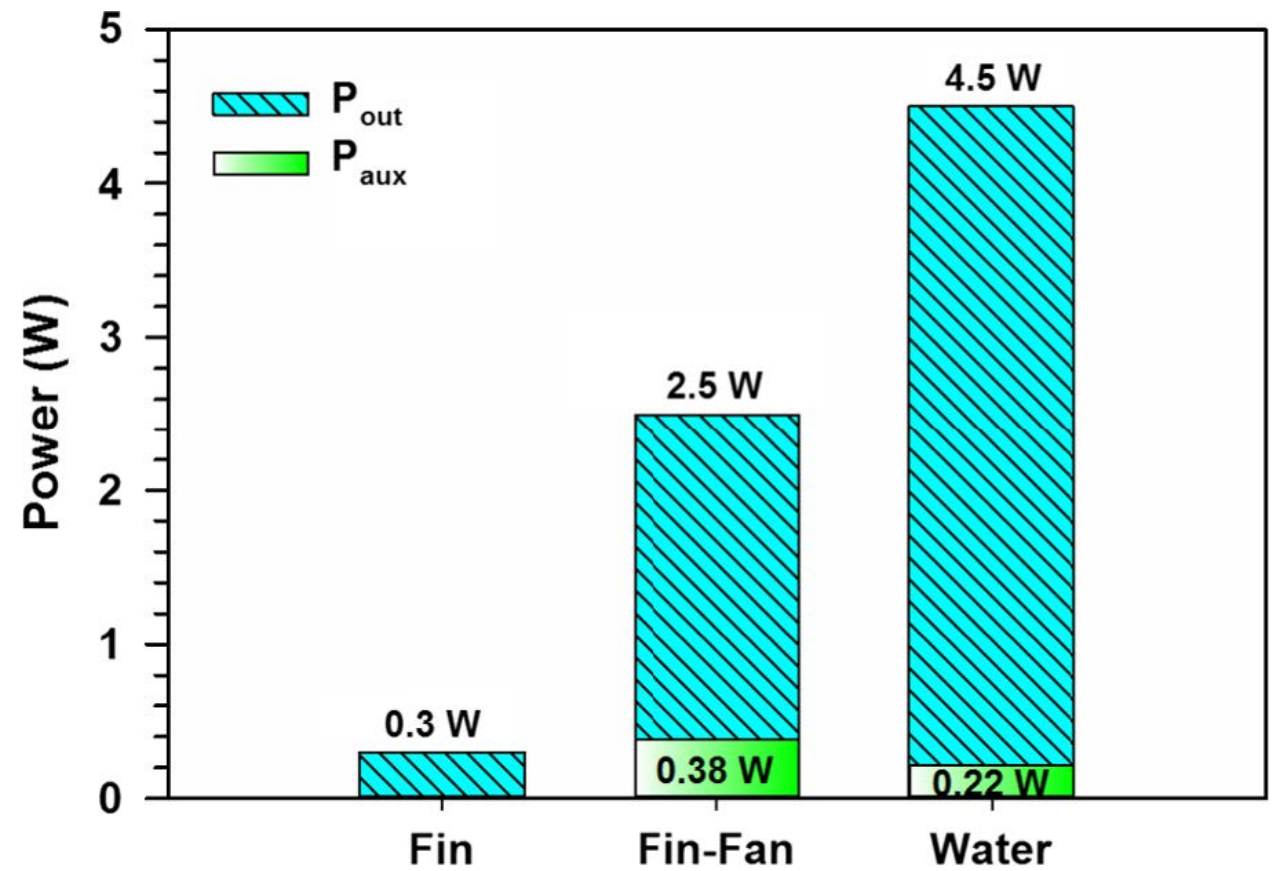

Figure 11. Net output power of the three different heat removal concepts. Reprint with permission [70]; Copyright 2021, Elsevier. 


\subsection{Microchannel and Minichannel}

In order to achieve the same heat flux density at a higher compactness, the hydraulic diameter of the channels can be shrunk. Three sizes can be distinguished [73]: The hydraulic diameter of conventional channels (macrochannels) is larger than $3 \mathrm{~mm}$. The minichannels have hydraulic diameters between $3 \mathrm{~mm}$ and $200 \mu \mathrm{m}$, whereas channels with hydraulic diameters smaller than $200 \mu \mathrm{m}$ are classified as microchannels. Investigations on microchannels and minichannels in combination with TEG are presented in the context of research objectives and research results.

Rezania et al. [74-79] studied the cooling of TEG with microchannels intensively. They compared the performance of microchannel and macrochannel heat sink numerically [74]. On one hand, for the arrangement of the same temperature difference between hot and cold surface of the TEG, the macrochannel needed less pumping power. In turbulent flow regime, the required pumping power was about $1.4 \%$ of the output power for the macrochannel, whereas this number increased to approx. $10 \%$ in the case of microchannel. For the laminar flow, the required pumping powers were much smaller, less than $0.1 \%$ for microchannel and less than $0.01 \%$ for macrochannel. As seen from this numerical study [74], the use of microchannel or macrochannel does not have a noticeable effect on the pumping power, whereas a slight penalty need to be considered for the microchannel, in the turbulent flow regime. On the other hand, the microchannel heat exchanger needs a lower flow rate, is more compact, and weighs less. They examined the maximum net output power experimentally and found a single maximum, when varying the coolant flow rate [77]. It shifted to lower flow rates when the temperature difference of the TEG surfaces was decreasing. They have studied the effectiveness of the number of microchannels under a TEG numerically, by reducing the number of channels while holding the pressure drop constant [76]. This reduced the velocity in the channel and, the thereby the pumping power. They stated that a small number of channels is sufficient for a TEG, but the inlet plenum needs to additionally be considered in the loss calculation, especially at high pressure drops. The channels were equidistantly distributed under the TEG, also utilizing the space between the legs (gaps). The channels between the legs removed significantly less heat than the channels under the legs [75]. This fact was further investigated by removing the microchannels under the gaps in flow direction and by combining the microchannels to a macrochannel under the gaps perpendicular to the flow direction as shown in Figure 12 [79]. They numerically found out that the maximum net output power with this configuration was the same as before, but obtained at a higher flow rate. In addition, the cost efficiency was also optimized [78]. Both the microchannel heat exchanger geometry and the TEG geometry were varied, and by aiming at a maximum output power, a specific geometry was found. It was also found that there was a unique pumping power, which produced maximum cost performance for the TEG system.

Kiflemariam and Lin [80] studied the concept of self-cooling numerically, where no external power was needed to cool actively a heat source. The heat flowed through a TEG, which delivered the electrical power to drive a pump, which pumped water through a microchannel heat exchanger cooling the TEG and through a passive finned secondary heat exchanger conducting the heat to the environment (Figure 13). The model was validated with the experimental work of Rezania et al. [77] and could even predict a positive net output power under optimal conditions.

Abdo et al. [81] used a 3D printed microchannel heat exchanger to cool a combination of photovoltaic (PV) cell and TEG. It was printed by laser sintering of maraging steel with a thermal heat conductivity of $11.4 \mathrm{~W} \cdot \mathrm{m}^{-1} \cdot \mathrm{K}^{-1}$. To achieve a high temperature uniformity for the PV cell, the heat exchanger had two inlets and two outlets. Each string served as the primary cooling of another part of the PV surface and they could operate under parallel or counter flow condition. The experimental setup, the $3 \mathrm{D}$ printed heat exchanger and the flow structure of the heat exchanger are depicted in Figure 14. 


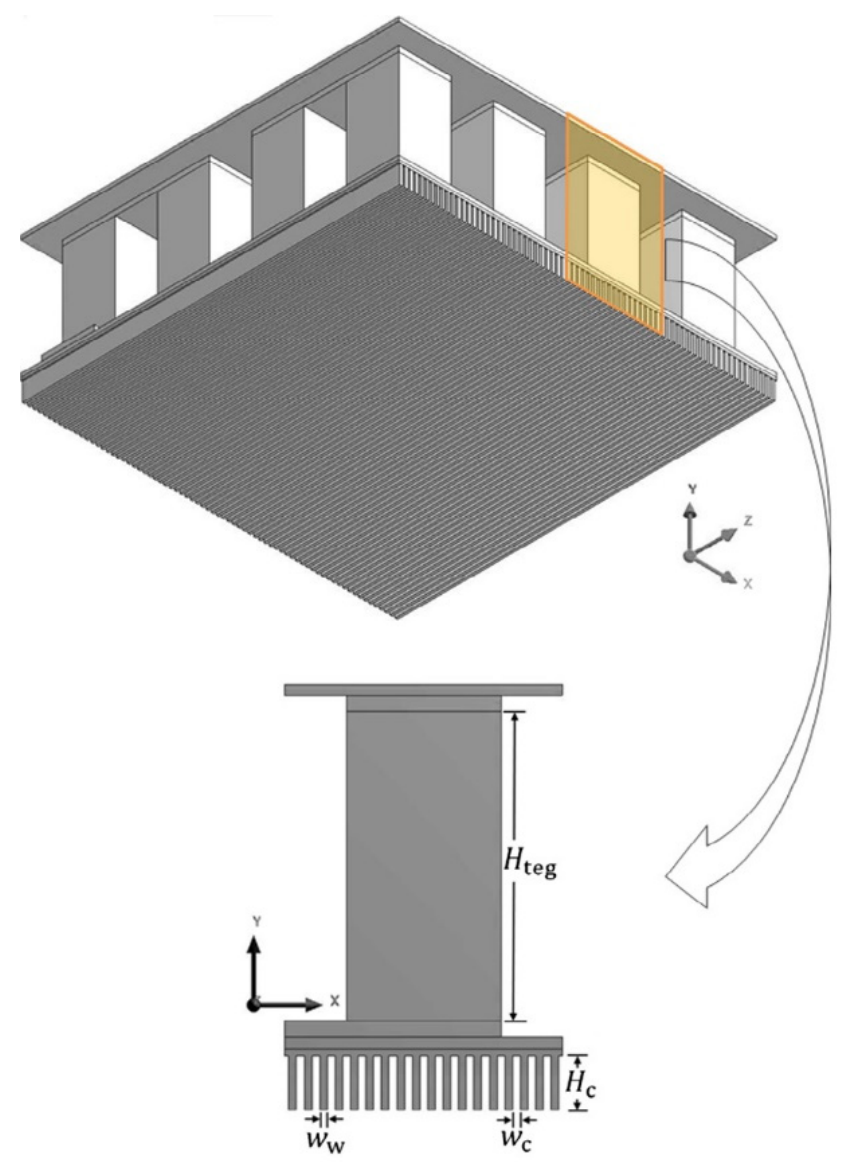

(a)

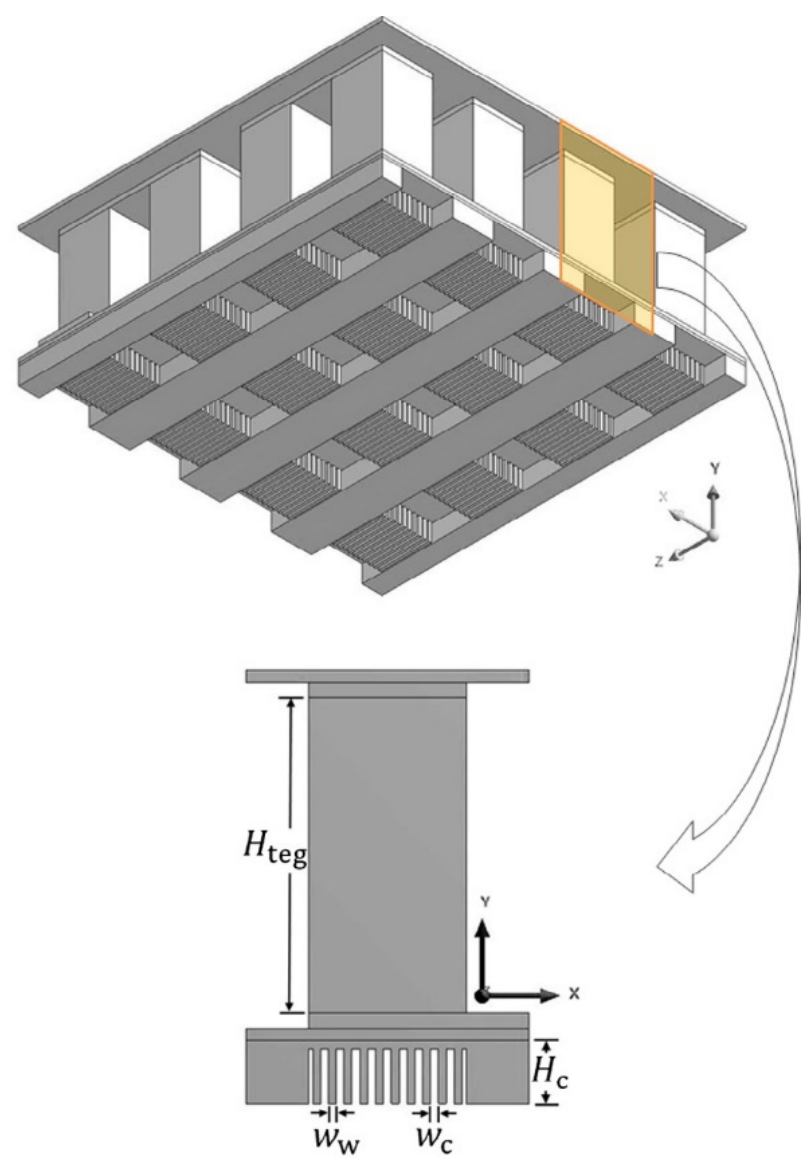

(b)

Figure 12. Two different kind of microchannel heat exchanger arrangements: (a) plate-fin heat sink; (b) cross-cut heat sink. Reprint with permission [79]; Copyright 2021, Elsevier.

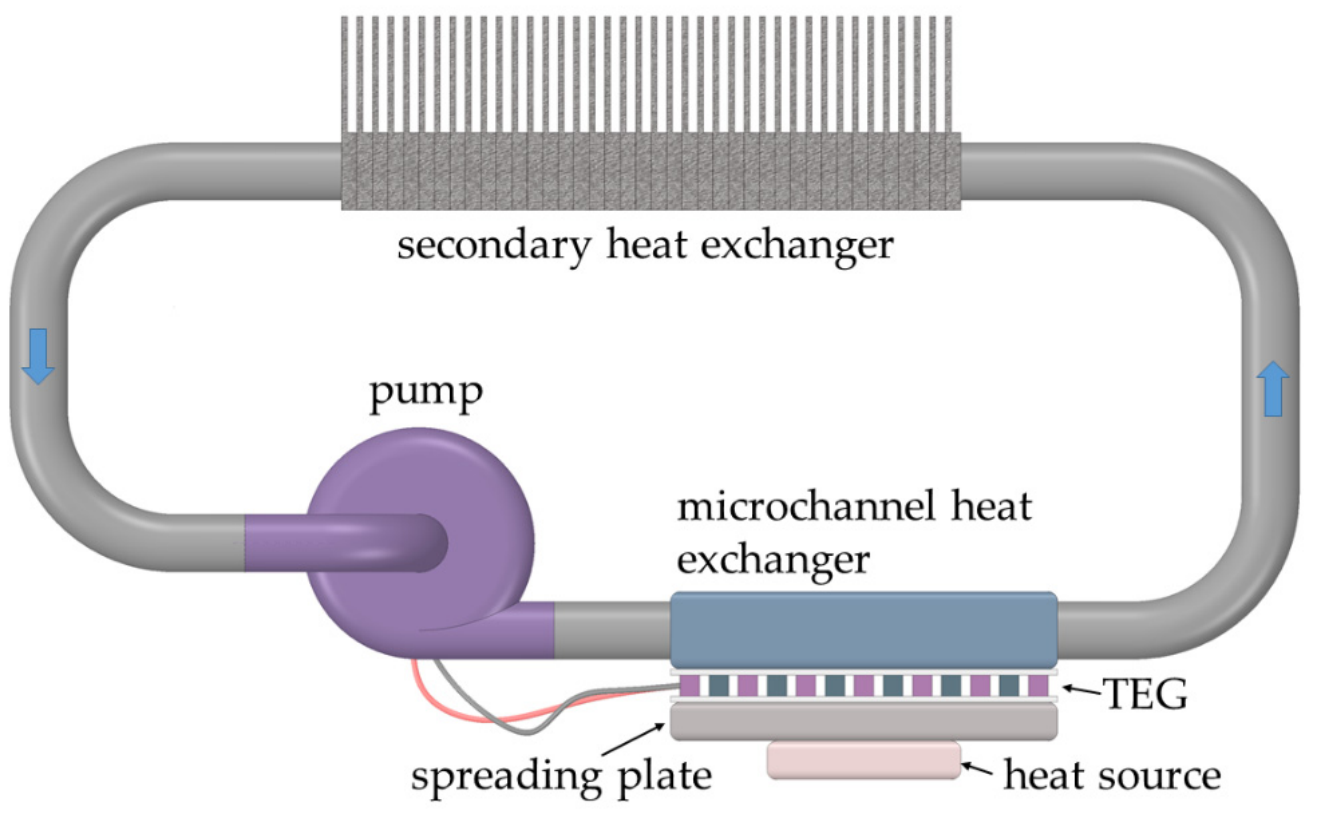

Figure 13. Self-cooling system with microchannel heat exchanger cooled TEG (Redrawn based on the figure provided in [79]). 


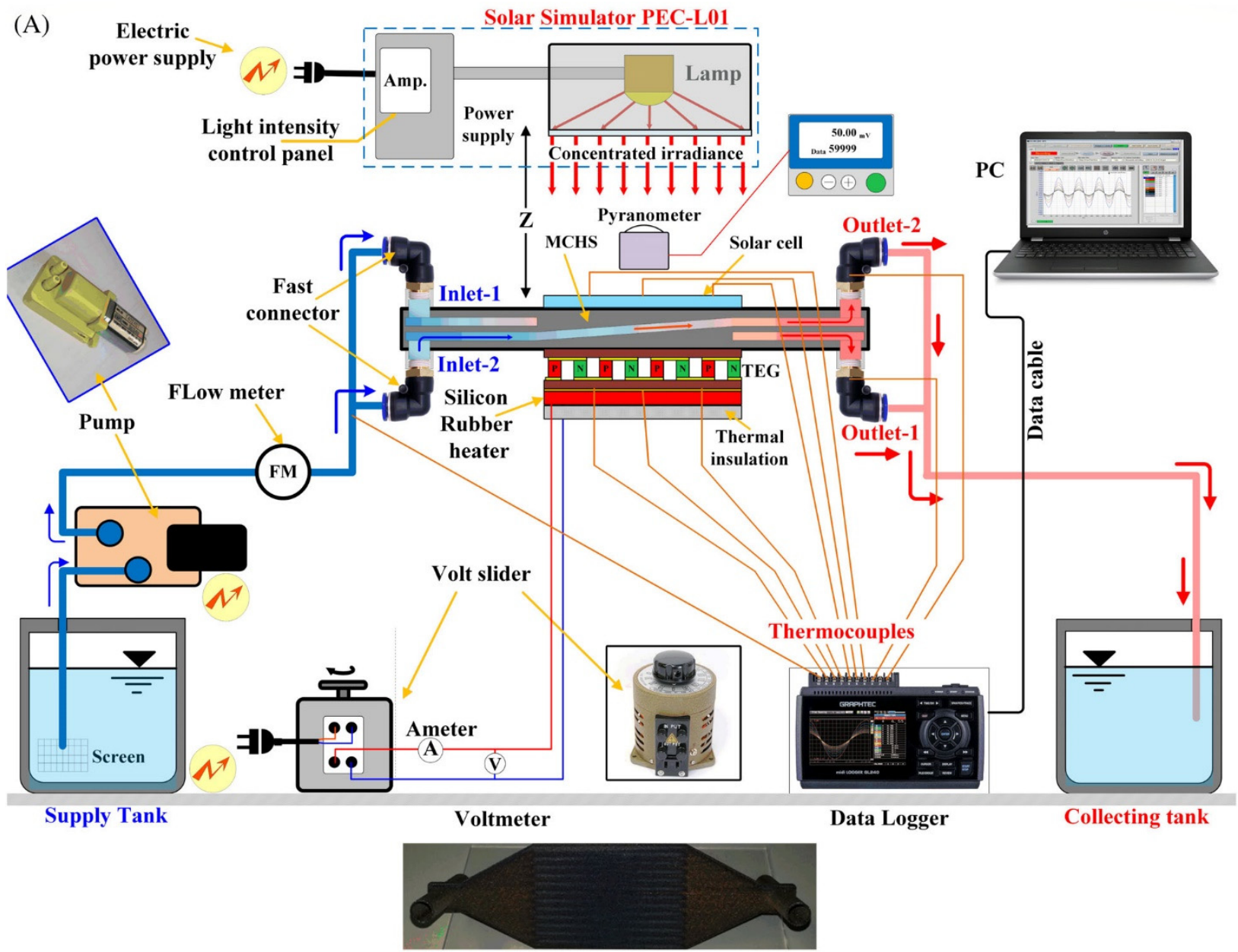

(B)

Real photo of the MCHS
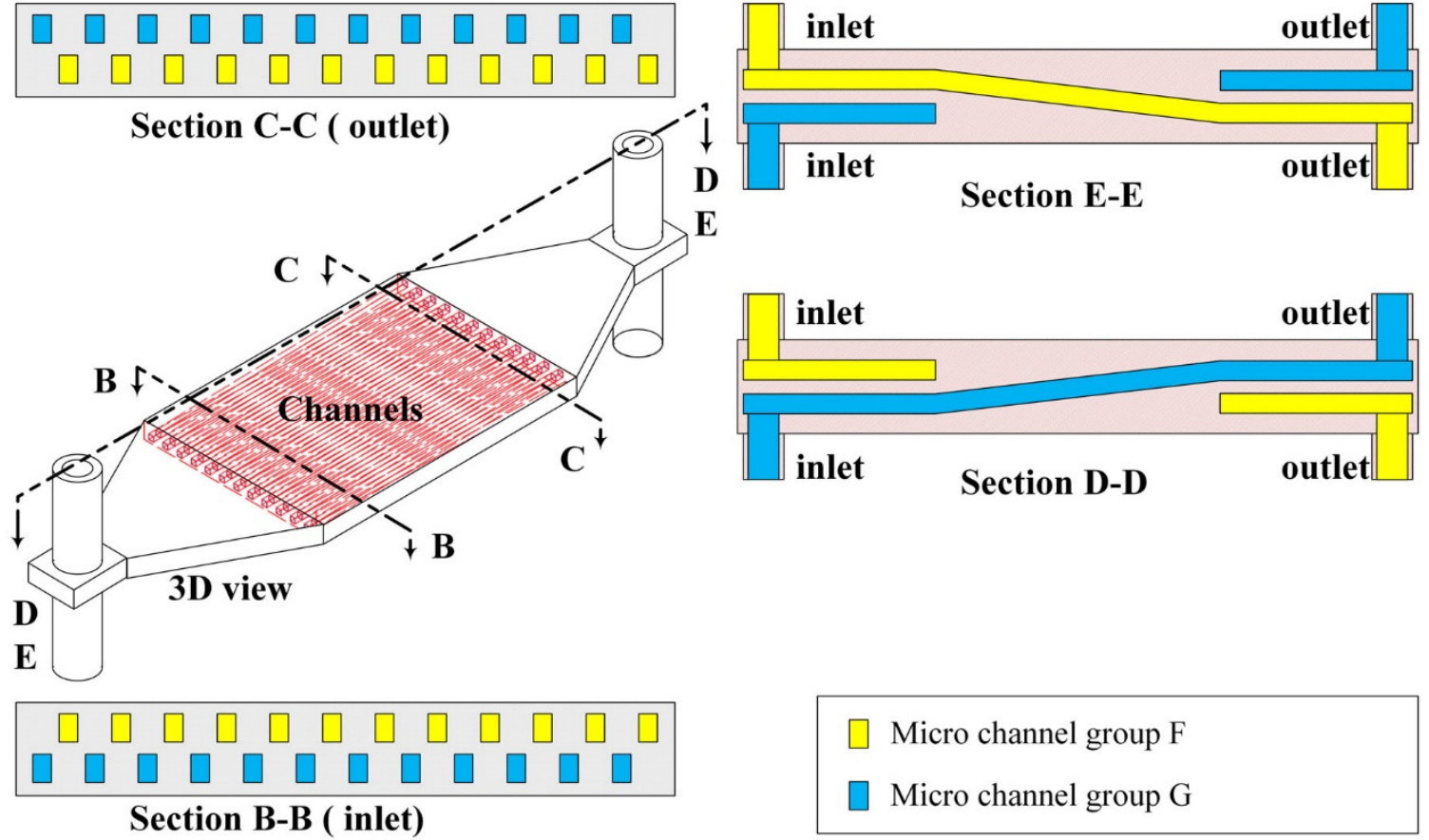

Micro channel group F

Micro channel group G

Figure 14. PV microchannel TEG System. Schematic of: (A) the experimental setup; (B) the 3D metal printed microchannel heat exchanger. Reprint with permission [81]; Copyright 2021, JOHN/WILEY \& SONS LTD. 
Lee and Lee [82] conducted a study of TEG in combination with printed circuit heat exchanger (PCHE), where minichannels were manufactured by photochemical etching on metal plates with a diameter of $2 \mathrm{~mm}$, to achieve a very compact system. 48 TEG were sandwiched between five PCHEs, two operating with a synthetic organic heat transfer fluid, and three operating with cold water. A maximum net output power of $192.6 \mathrm{~W}$ could be obtained experimentally. A computational fluid dynamics (CFD) model was used to determine the thermal resistance and pressure loss (Figure 15). It was found that the maximum net output power was obtained for lower Reynolds numbers, as the difference in the inlet temperatures decreased. The compactness and the low flow rate of the created system was particularly emphasized in this work, in comparison to a simple single conventional channel with the width of one TEG.

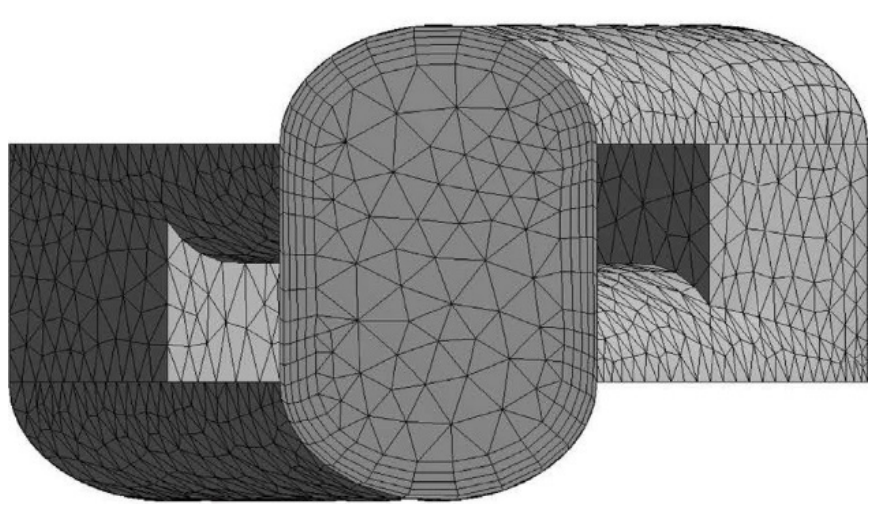

(a)

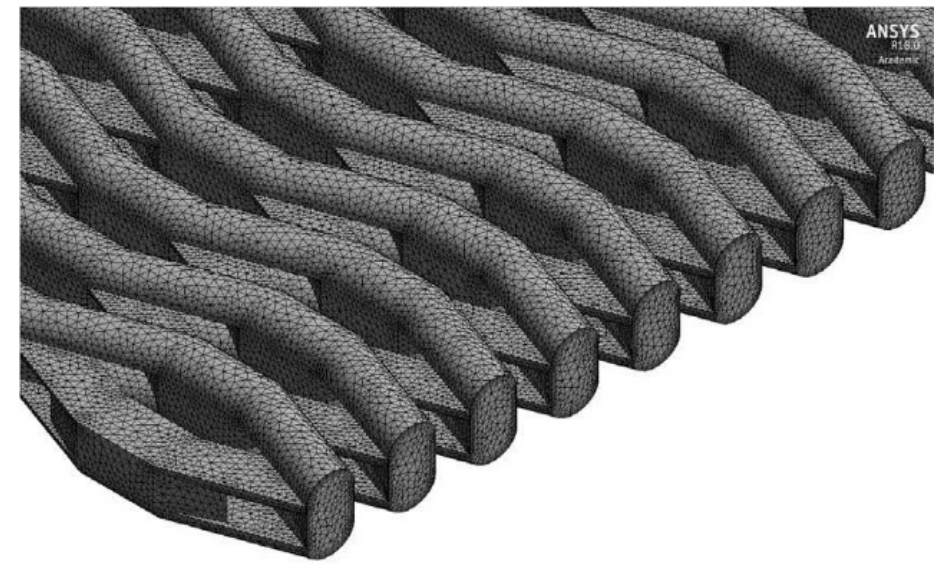

(b)

Figure 15. Computational mesh of CFD analysis performed by Lee and Lee: (a) Mesh of each channel; (b) Mesh of fluid part at main region of heat exchanger. Reprint with permission [82]; Copyright 2021, Elsevier.

Abd El-Samie et al. [83] created a numerical model to investigate a solar powered TEG cooled by a zigzag microchannel heat exchanger with nanoparticles added to cooling water. The results showed that Reynolds numbers higher than 400 and the nanoparticle concentration had no influence on the output power of the TEG. A Reynolds number of 50 provided the maximum net output power for this system, as can be seen in Figure 16.

Not only the cooling channels can be of micro-size, also the TEG itself can have microsize dimensions ( $\mu$ TEG). Wojtas et al. [84] used at $\mu$ TEG $(10-400 \mu \mathrm{m})$ in combination with a microchannel heat exchanger $(20-80 \mu \mathrm{m})$, as shown in Figure 17, to optimize the net output power numerically and experimentally. A single maximum for the net TEG output power was reported when varying the cold flow rate. The maximum shifts when the hot flow rate, the channel width or channel height changes. The results were validated and the importance of the net output power was demonstrated by the resulting negative values under inappropriate conditions.

Net output power was the main criterion for a design optimization of a $\mu$ TEG in the investigation of En Heng et al. [85] as well. The developed numerical model consisted of a poly-Si $\mu$ TEG and a microchannel cooler. The optimal channel size for this configuration was $50 \mu \mathrm{m}$ in height and $50 \mu \mathrm{m}$ in width. The net output power was only positive in a narrow range of the flow rate up to $0.06 \mathrm{~m} \cdot \mathrm{s}^{-1}$. Beyond this value, the yield was completely consumed by the additional required pumping power. 


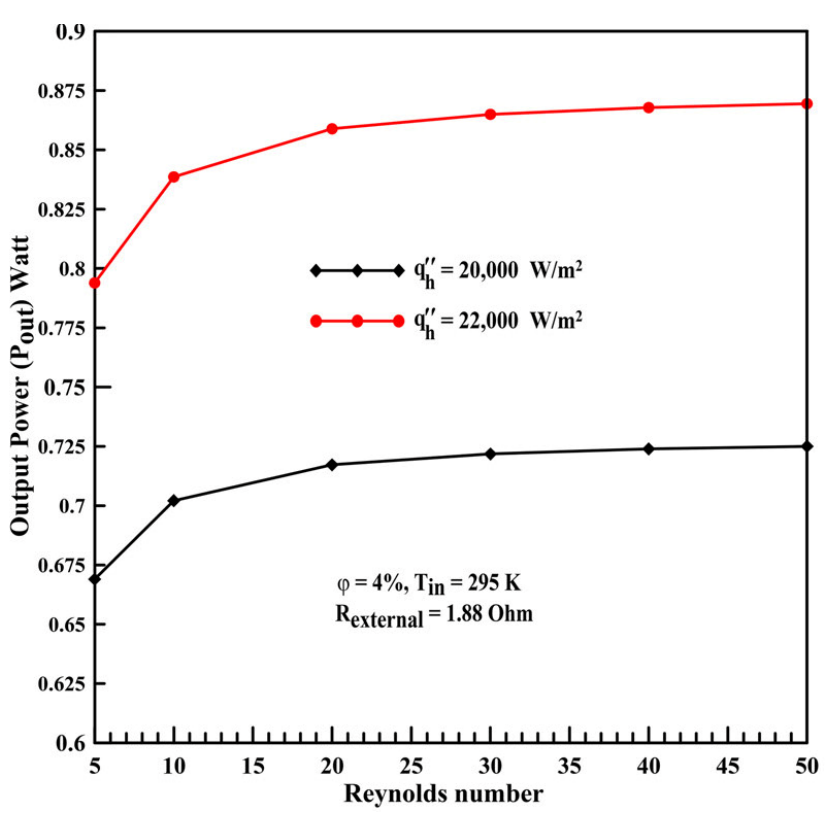

(a)

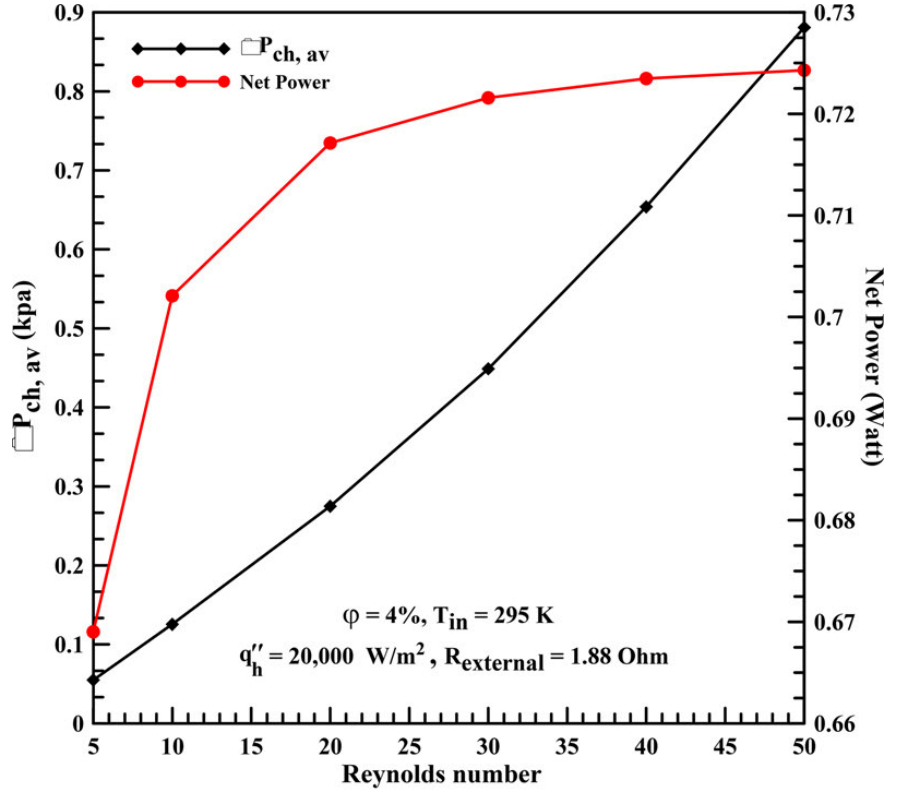

(b)

Figure 16. Solar powered TEG cooled by a zigzag microchannel: (a) Output power versus the low range of Reynolds number at two heat fluxes; (b) Average pressure drop and net output power versus the Reynolds number. Reprint with permission [83]; Copyright 2021, Taylor \& Francis.

(a) Polymer

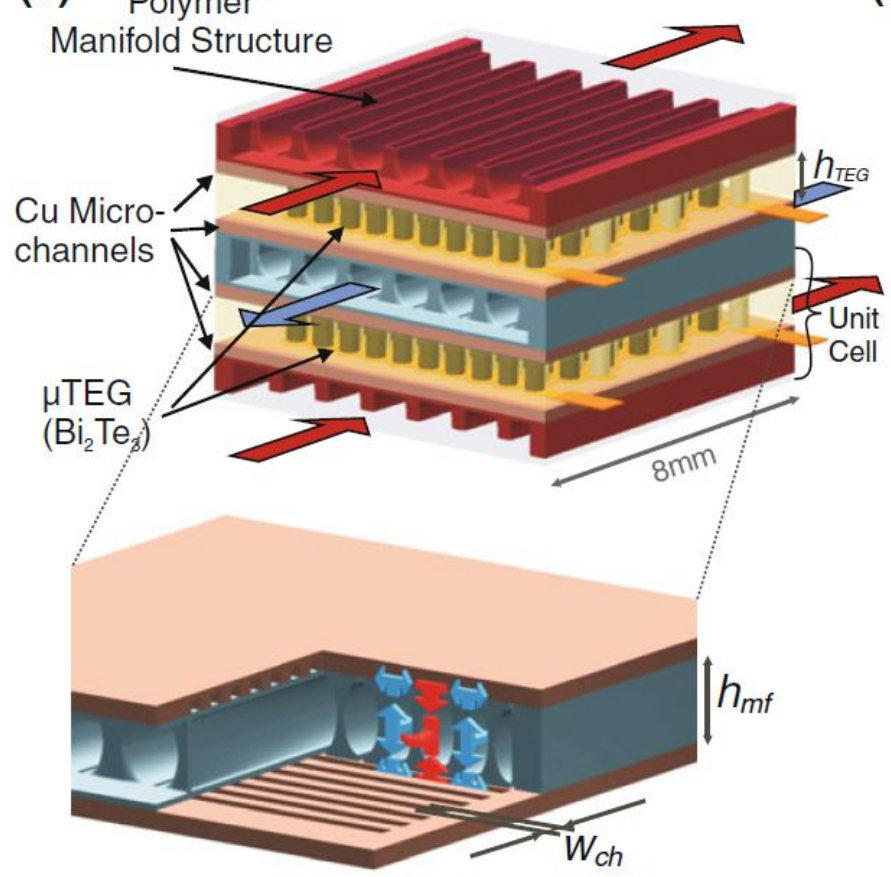

(b)

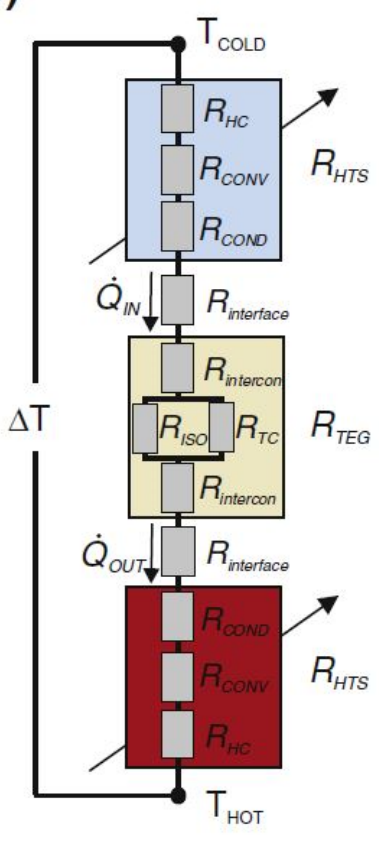

Figure 17. $\mu$ TEG microchannel heat exchanger system: (a) Schematic drawing with enlarged view of the multilayer heat transfer system; (b) Equivalent thermal resistance network of one unit cell. Reprint with permission [84]; Copyright 2021, Springer Nature.

\subsection{Impingement}

The shrinking of channels to mini or macro size achieves the advantages described above. In order to induce flow through the small channels, the pump must build up a high pressure but at a low flow rate to achieve a positive net output power. The situation is different with the impingement, where the pressure drop is rather lower but the flow 
rate is higher. With the impingement, the fluid is directed through a small hole or slot and impinges on the surface to be cooled. Compared to channel cooling, this allows higher Nusselt numbers to be achieved, locally. Studies involving the combination of impingement cooling and TEG are presented in this section. It shall, however, be noted that the net output power was not considered in the studies reviewed below.

In a numerical study, Suzuki et al. [86] investigated a TEG, which is heated by impingement on the one side, and cooled by suction on the other side. The injection and suction on opposite sides resulted in a counter flow such as situation. They reported a voltage which was close to that of a counter flow channel cooling (only 1\% smaller). It was also reported that the pressure drop was much smaller compared to a conventional channel flow, without, however, a quantification of the pressure drop.

Pandit [87] 3D printed an impingement heat exchanger for automobile exhaust gas waste heat recovery, using a metal additive manufacturing process as shown in Figure 18. They revealed an efficiency improvement of $0.4 \%$ by using impingement jets compared to the baseline case. In the impingement case the baseline channel was extended by an impingement barrier, which forced the flow to impinge on the cold surface of the TEG.

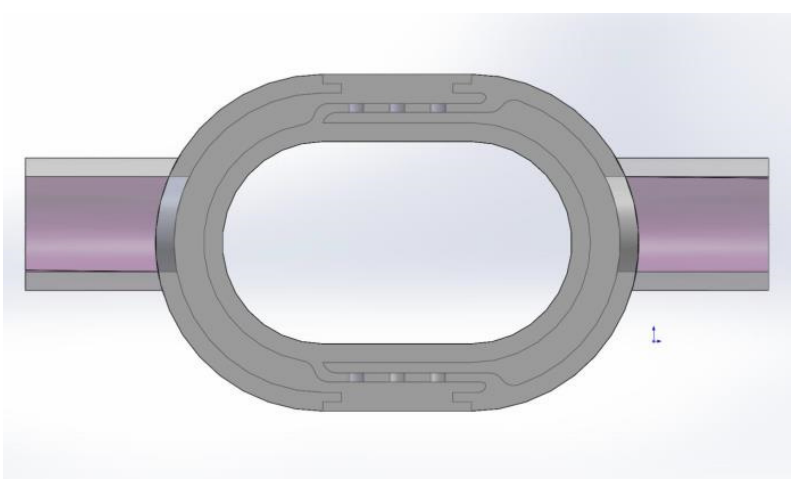

(a)

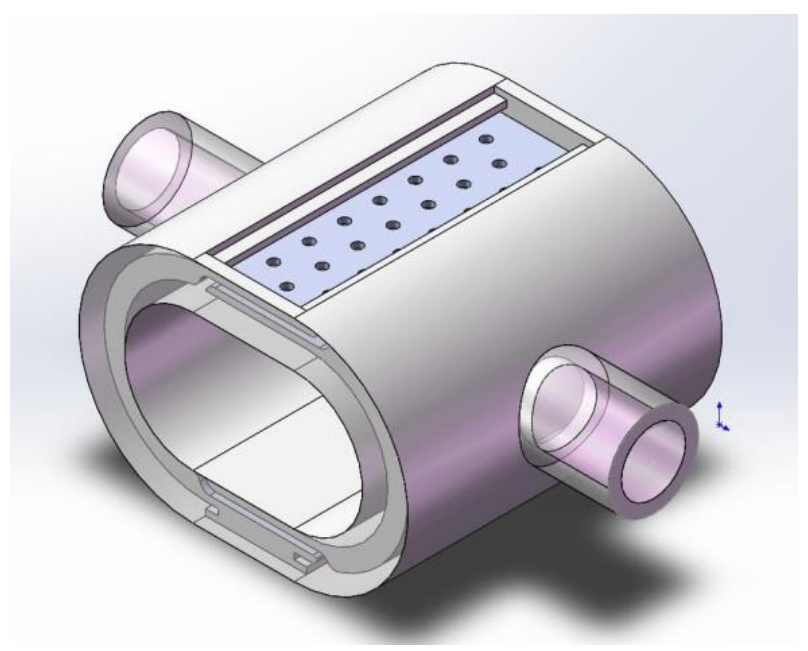

(b)

Figure 18. Cold side impingement jet geometry of a automotive TEG system (a) Front View; (b) Isometric View. Reprint with permission [87]; Copyright 2021, Dr. Pandit.

Pfeiffelmann et al. [88,89] reported a new solver within an open source CFD framework to model a TEG and the flow of the heat exchanger at once. Two ingredients of the complete model, i.e., the TEG, and the impingement cooling configuration were, considered separately, first, in order to validate the numerical models in detail, by comparisons with the relevant experiments from the literature. After validating the two parts, they combined both to a coupled model. The results of such a calculation can be seen in Figure 19, where the predicted streamlines of the cooling water flowing over the TEG legs are displayed. 


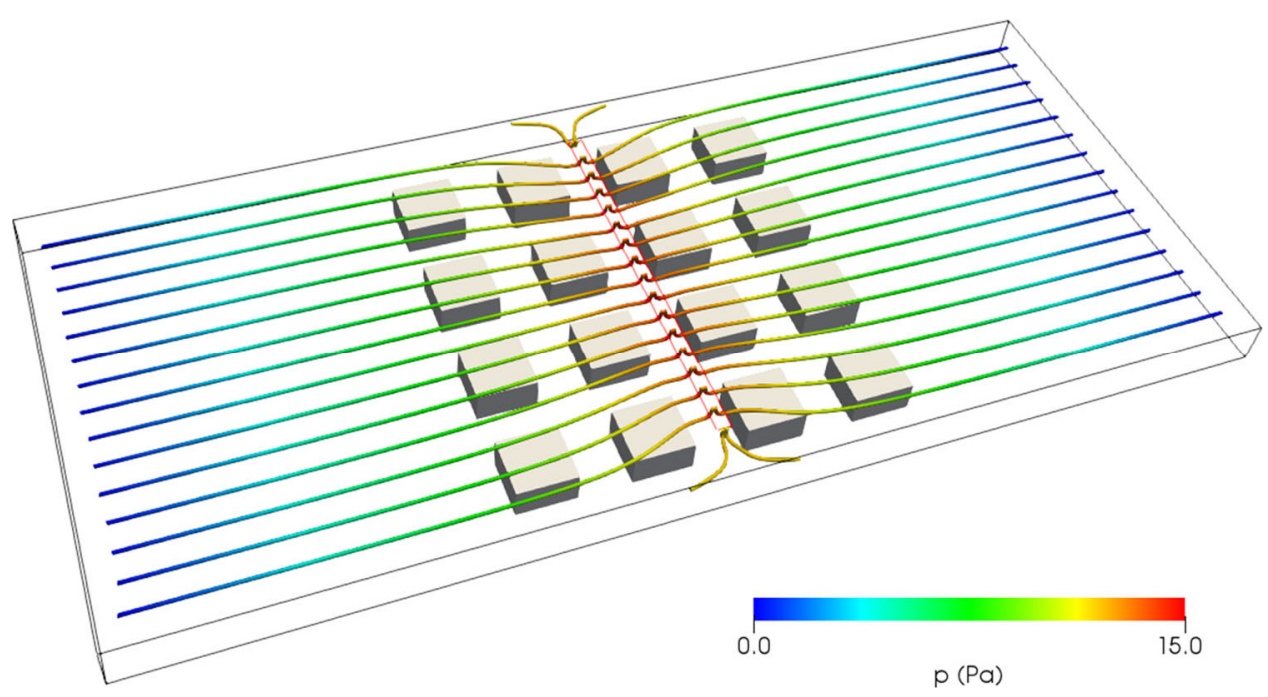

Figure 19. Predicted streamlines colored by a gauge static pressure. Reprint with permission [89]; Copyright 2021, Taylor \& Francis.

\subsection{Inserts}

In order to change the flow pattern and thus enable more efficient heat transfer in heat exchangers, inserts have been used for a very long time [90]. This is also the case in the cooling of TEG, as for example in the increase of efficiency by fins in the channel in a solar TEG system [91,92]. Ribs and other insert geometries with associated research results are now presented.

Qiang et al. [93] performed a multi-objective optimization of fin inserts in a water heat exchanger, cooling a TEG for automobile application. The optimization was conducted with design of experiments and archive based micro genetic algorithm. They defined a compensation coefficient. They found that, the transversely arranged fins performed better than the longitudinally arranged fins (Figure 20). They reported that three candidates were fulfilling the requirement of cooling performance and pressure drop, but only one had an optimal compensation coefficient.

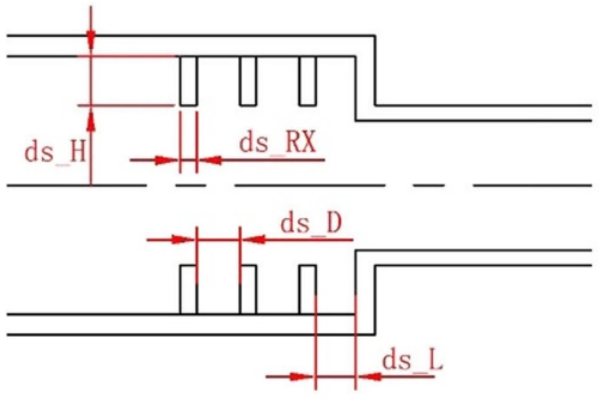

(a)

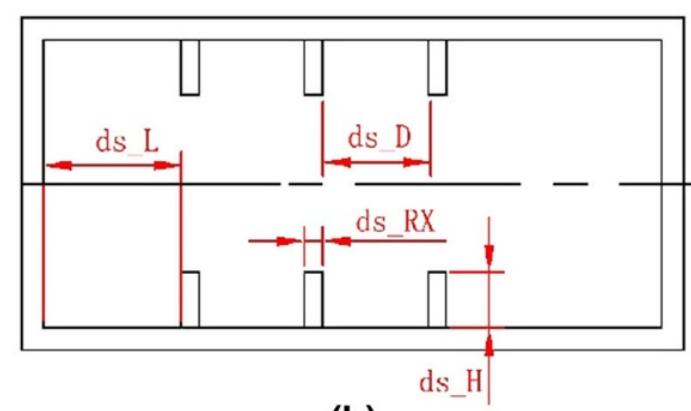

(b)

Figure 20. Arrangement of fins in a water heat exchanger: (a) transversely; (b) longitudinally. Reprint with permission [93]; Copyright 2021, Springer Nature.

Fin inserts were also used by Zhou et al. [94] who rotated the fins by $60^{\circ}$ with respect to the channel to induce a chaotic flow, as depicted in Figure 21. By using the fins, changing the size of the channel from macro to micro-scale and by using nanoparticles, the previous work of Zhou et al. [52] was extended numerically. Due to the fins, the maximum net output power shifts towards the laminar flow regime and thereby to the micro-scale. An improvement of $30 \%$ of the net output power could be achieved. The loaded $\mathrm{CuO}$ nanoparticles performed superior only in the micro-scale, where the velocity was low, with an improvement of $38 \%$ in power generation. 


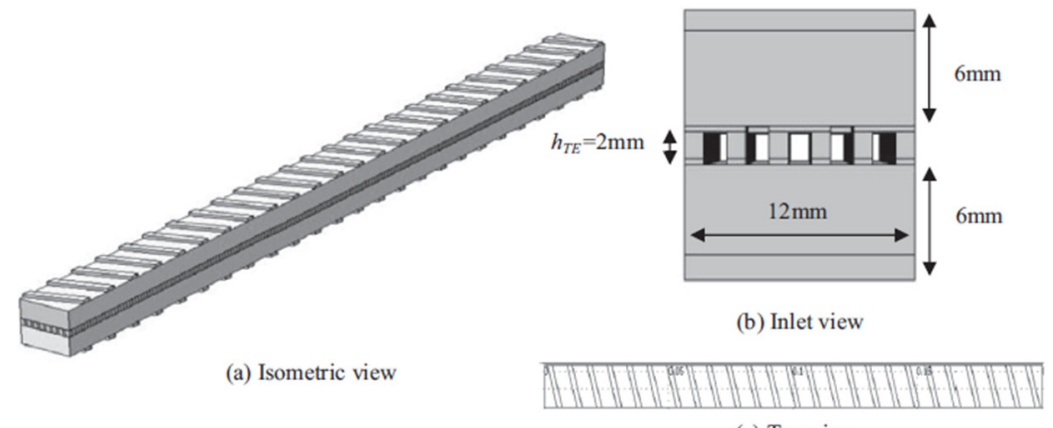

(c) Top view

Figure 21. Channel with rotated fins. Reprint with permission [94]; Copyright 2021, Elsevier.

Bjørk et al. [95] used fins to enhance the performance of the cooler (water) and heater (oil) channels of a TEG system as well. A small, with 4 or 6 TEG, and a large, with 100 TEG (Figure 22), system were experimentally investigated. The study was extended with a numerical model of the system by Sarhadi et al. [96]. The main part of this study focussed on the thermal interface material on the TEG surface and lead foil performs best. Moreover, the net output power was calculated for variations of the finned channel geometry. For their flow condition, they showed that the wider channel accomplished better compared to the longer channel with the same amount of TEGs. The maximum net output power was not attainable within the range of the used flow rates.

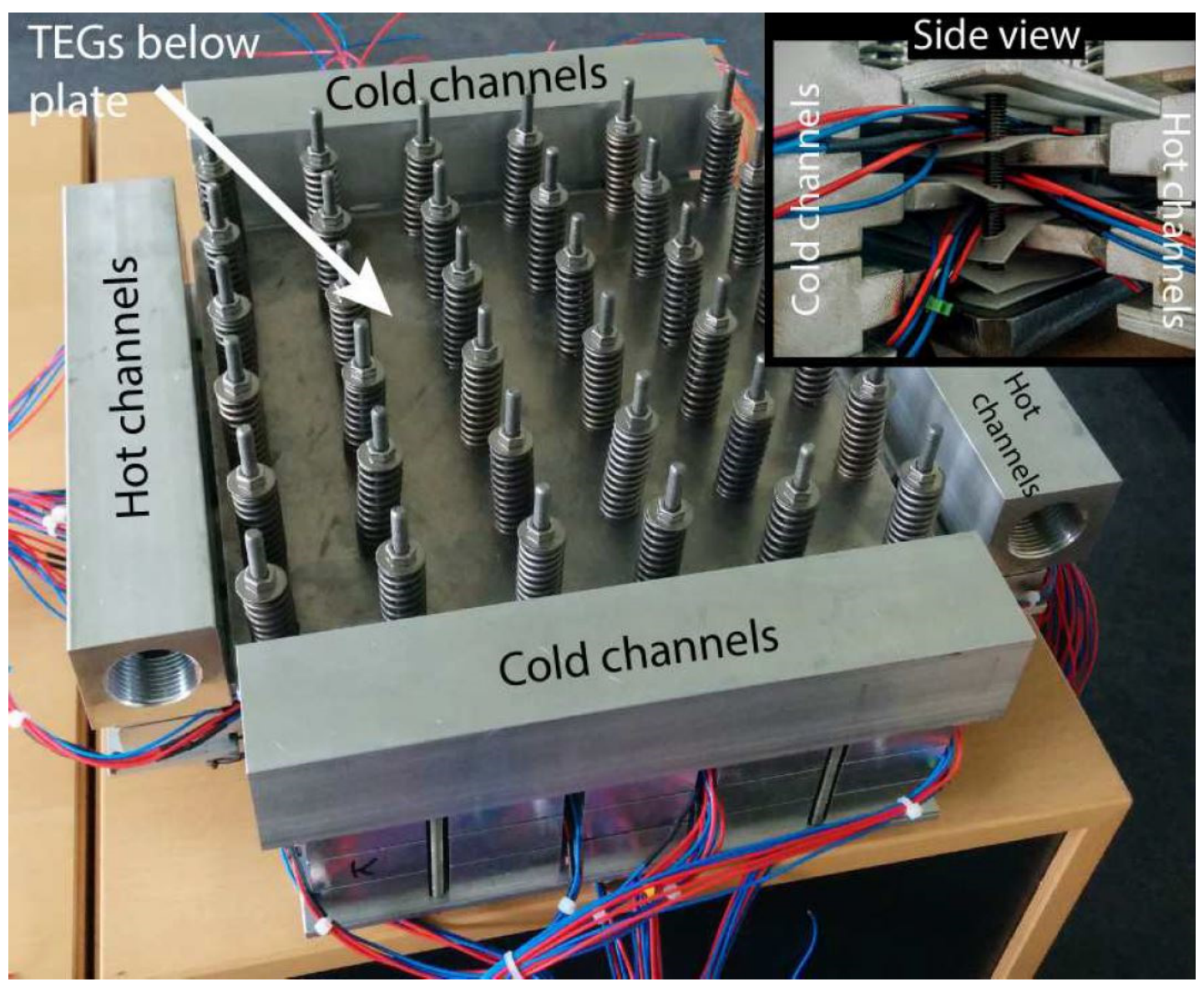

Figure 22. Experimental setup of a fluid-fluid TEG system with fins in the channels and 100 TEGs. Reprint with permission [95]; Copyright 2021, Elsevier.

Flat surfaces, fins and cylindrical grooves were examined by Zhu et al. [97] to improve the cooling of TEG (Figure 23). The developed numerical model was validated with the 
experimental results of the flat surface water heat exchanger. Additionally, the channel height of the grooved version was varied. The efficiency was assessed with a comprehensive efficiency factor relative to the flat surface, which uses the Nusselt number and friction factor. The assessment showed that the grooves with the grooves-depth ratio of 0.081 performed best.

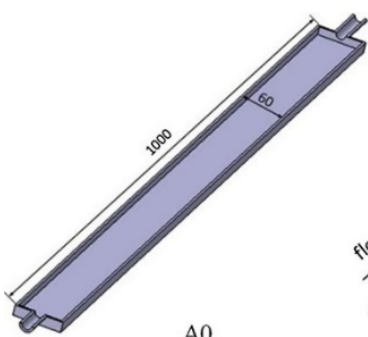

$\mathrm{A} 0$

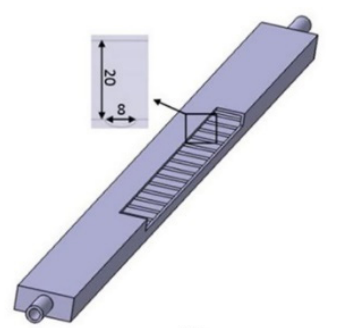

$\mathrm{A} 2$

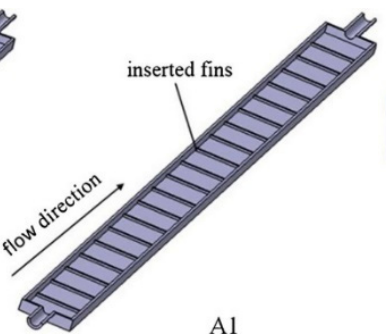

$\mathrm{Al}$

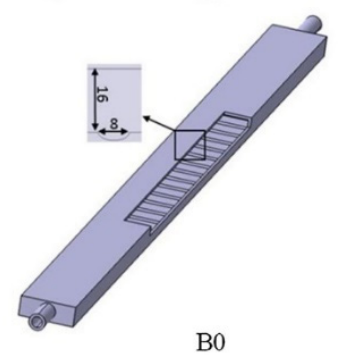

B0

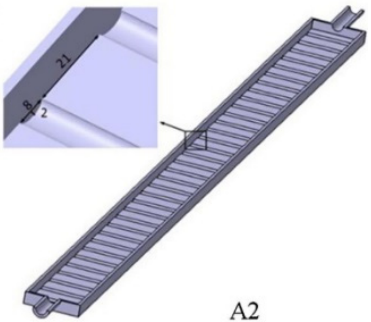

A2

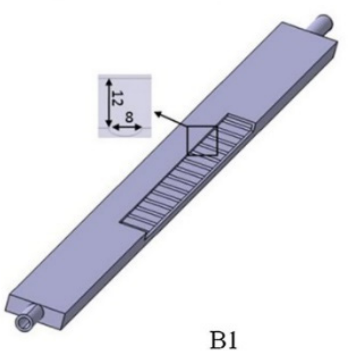

B1

Figure 23. Cooling units with five different inner topologies-empty, fins and grooves with different channel heights (units: mm). Reprint with permission [97]; Copyright 2021, Springer Nature.

In the aforementioned study of Du et al. [62] they also enhanced the water cooling by using baffler and achieved an improvement of the output power. They reported a negligible increase of pumping power by using the bafflers, due to the low velocity of the water.

Wang et al. [98] investigated the influence of metal foam inserts on the performance of hot and cold heat exchangers connected to a TEG experimentally, as illustrated in Figure 24. Oil was flowing through the hot heat exchanger, and water was flowing through the cold one. The maximum output powers of the metal foam filled and unfilled systems were $9.8 \mathrm{~W}$ and $7.7 \mathrm{~W}$, respectively. The net output power increased as well, and an improvement of $33 \%$ was achieved by using the metal foam insert.

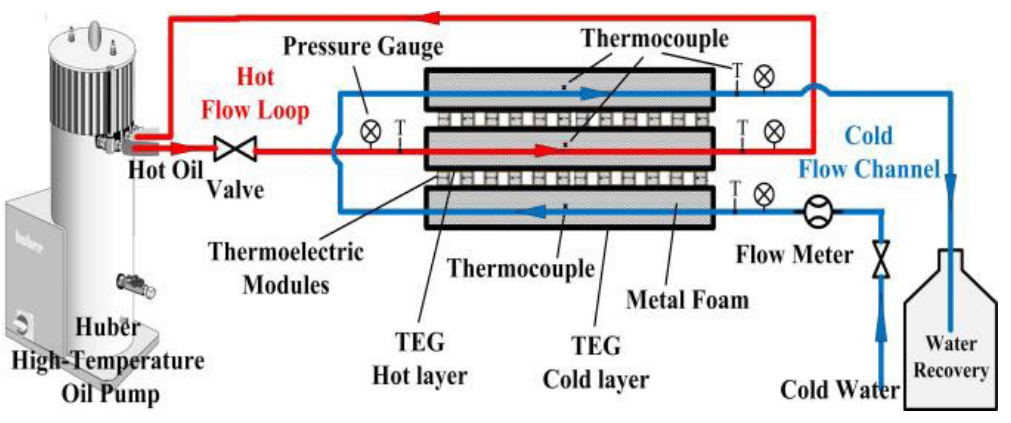

(a)

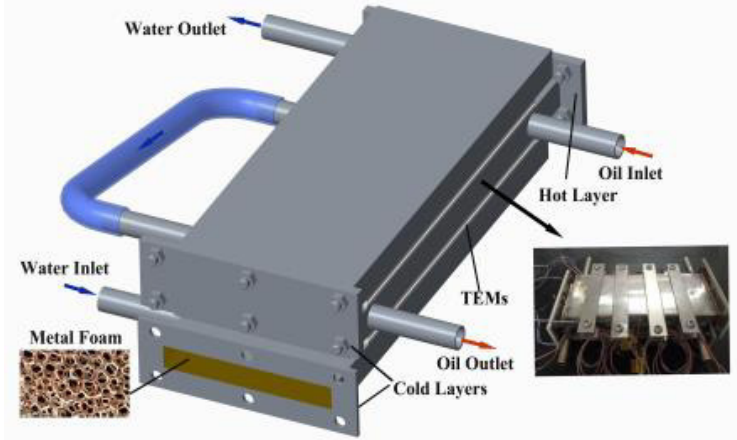

(b)

Figure 24. Schematic of the TEG system consisting out of channels filled with metal foam: (a) Experimental setup; (b) Prototype. Reprint with permission [98]; Copyright 2021, Elsevier.

A TEG system with hot and cold liquid heat exchanger and 40 TEG was investigated by Amaral et al. [99,100], and Sempels and Lesage [101] as well. The temperature difference between both inlets was fixed to $70.6{ }^{\circ} \mathrm{C}$ but flow rates were varied. Furthermore, turbulating inserts, steel stripes with punched panels (Figure 25) with different spacings 
were implemented into aluminium plates with embedded aluminium pipes to enhance the cooling. The output power of the TEG tended to an upper limit when the panel density was increased or when the flow rate was increased. This led to an optimum value of panel density and flow rate considering the net output power, because the pressure drop was increasing continuously when both parameters were increased.

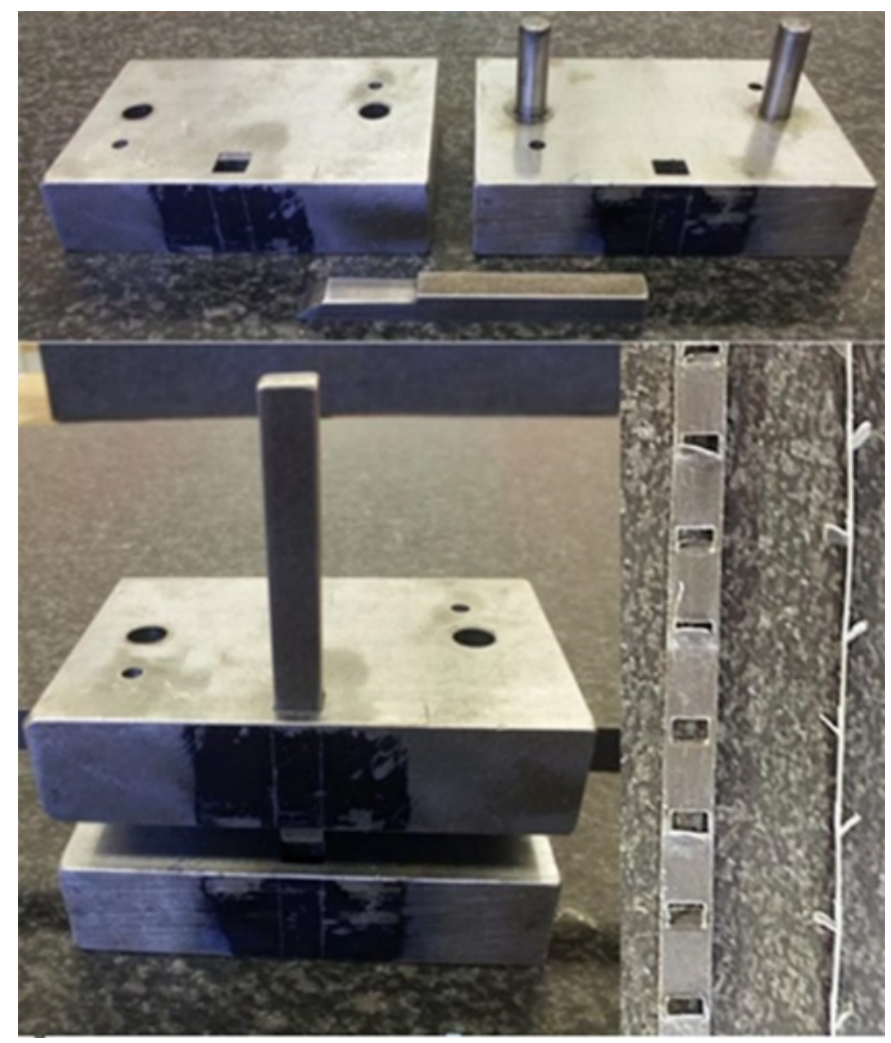

Figure 25. Flow obstructing inserts used by Amaral et al. with the punching tool for making these. Reprint with permission [99]; Copyright 2021, Elsevier.

\section{Discussion}

As derived in Section 2, the net output power for water cooling is dependent on the hydraulic power. Therefore, an increase in hydraulic power must be weighed against the increase in electric output power. This is confirmed in all papers that consider net output power. A single maximum of net output power can be detected when the flow rate is allowed to increase from standstill. The optimum is not at the maximum output power of the TEG, which is at the maximum flow rate or at the lowest thermal resistance of the heat exchanger. The net output power can take negative values in the worst case. In addition, the optimum is dependent on the temperature difference. With increasing temperature difference, the optimum flow rate also increases. Since, the cost performance depends, inter alia, on the net output power, it also reaches its maximum before the maximum output power [78]. Turbulence is not the decisive criterion for the position of the optimum. The optimum can be in the turbulent region [52], in the transitional region as well as in the laminar region [83] and this depends on the temperature difference as described before [82].

There are different geometrical designs of conventional channels. However, a comparison related to the net output power, and therefore the associated competitive evaluation of the designs used in the studies, is difficult. The difficulty lies in the dependence on the performance of the selected TEG in the respective studies. In a fair comparison, all TEGs in the studies should have been similar. However, this is not the case and this is reflected, for example, in the dispersion of the output power $\mathrm{P}_{0}$ in Table 1 . The table consists of values taken directly from the publications and values read from the included graphs, which is why the values can be inaccurate. Having such uncertainties in mind, in a 
comparison of the results displayed in Table 1 can still be attempted. Doing so, one can see that the highest net output power and the lowest ratio of hydraulic power to net output power ( $r$, introduced in Section 2) was recorded in the numerical work of Du et al. [62]. Here, a conventional channel was used, the result of which could be further increased by incorporating bafflers. The highest net output power was reported in the experimental work of Su et al. [49], where, again, a conventional channel was used. In contrast, the lowest power ratio (r) determined by an experimental setup was obtained by microchannel cooling [77]. Although inserts increase hydraulic power, they increase net output power. As can be seen in the last four rows of Table 1, the net output power of the TEG can be increased by inserts in all direct comparisons, with and without inserts, and should always be considered in the design.

Comparing the macrochannel and microchannel, one can see that the results are rather close. The microchannel provides only a marginal improvement in terms of the power ratio (r), compared to the macrochannel (Table 1). Since the production of the microchannel is much more complex, this slight improvement in the power ratio may not be seen sufficient to favour microchannel against macrochannel. On the other hand, if the heat flux is the same, the microchannel offers higher compactness, and this can be an additional argument for the use of microchannel, while, on the other hand, the associated higher pumping power (hydraulic power), shall also be considered in the overall assessment. However, looking at Table 1 one can see that the power ratio (r) is not markedly high compared to the other cooling methods, but especially when compactness is required, the additional manufacturing effort of microchannel is tolerable. In the previous experimental work on the use of inserts, it was possible to make direct comparisons between the cases with and without inserts. However, a direct comparison between microchannel and macrochannel for the cooling of TEG under the objective of net output power has not been studied experimentally yet. Only the numerical study by Rezania et al. [74] provides evidence that conventional channels outperform microchannels in terms of net output power. The review showed that the fabrication of microchannels and minichannels can be carried out in several ways, milling, 3D printing, and photochemical etching.

Impingement cooling has very rarely been used to cool TEG. Among the few studies, there are no studies on net output power and, similar to microchannel cooling, a direct comparison in terms of net output power is yet to be made.

Different results in the operation of hot fluid-TEG-cold fluid systems with respect to flow direction were obtained. In two papers, the counter flow configuration yields higher net output power $[49,51]$ and in one publication it is the parallel flow configuration that yields higher net output power [52]. The former result is more likely to be valid, since it was based on experimental studies.

Nanoparticles have either no effect [83] on the net power output, or have an effect only under certain conditions [94].

Of course, other factors also play a role when weighing up between the individual variants, such as manufacturability, costs or size. However, the downstream required power to extract the heat from the water should also not be neglected. It can be shown that a passive variant without an additional fan is preferable $[63,80]$. When both a heat source needs to be cooled and this heat should be recovered, and when the maximum temperature of the heat source to be cooled allows this, then self-cooling with TEG is an excellent way to save power.

Finally, it should be stated that the present findings do not support the thesis of Elghool et al. [3], who suggest that due to the low efficiency of TEG it is not advisable to cool them with liquid, instead of air. This has been disproved several times $[56,61,70]$. Despite the consumption of auxiliary components, a higher net output power could be generated in all cases. 


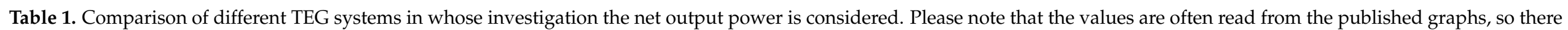
may be small inaccuracies.

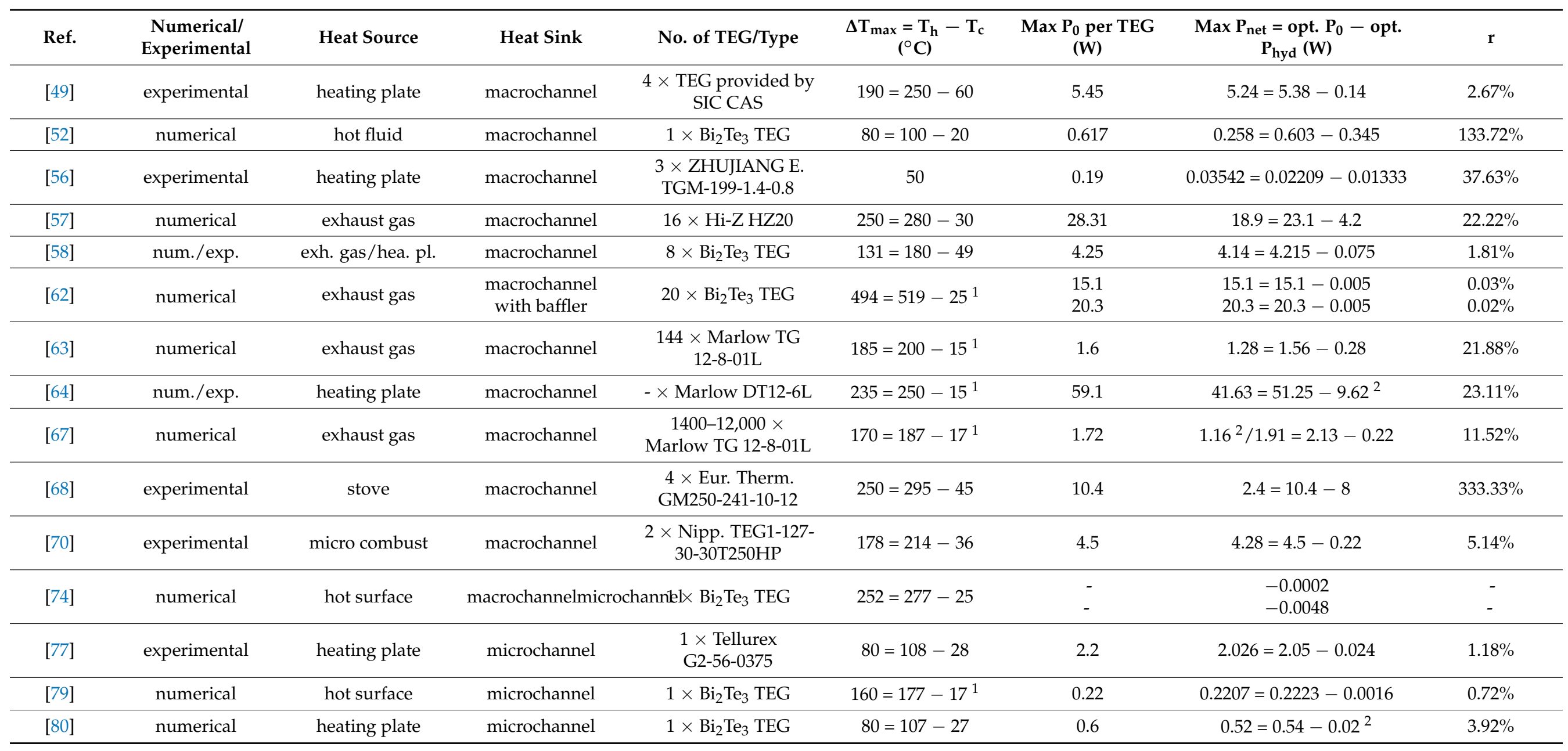


Table 1. Cont.

\begin{tabular}{|c|c|c|c|c|c|c|c|c|}
\hline Ref. & $\begin{array}{c}\text { Numerical/ } \\
\text { Experimental }\end{array}$ & Heat Source & Heat Sink & No. of TEG/Type & $\begin{array}{c}\Delta \mathrm{T}_{\max }=\mathrm{T}_{\mathrm{h}}-\mathrm{T}_{\mathrm{c}} \\
\left({ }^{\circ} \mathrm{C}\right)\end{array}$ & $\begin{array}{c}\text { Max } P_{0} \text { per TEG } \\
(\mathrm{W})\end{array}$ & $\begin{array}{c}\text { Max } P_{\text {net }}=\text { opt. } P_{0}-\text { opt. } \\
P_{\text {hyd }}(W)\end{array}$ & $\mathbf{r}$ \\
\hline [82] & num./exp. & hot fluid & minichannel & $\begin{array}{c}48 \times \text { Kryotherm } \\
\text { TGM-199-1.4-1.15 }\end{array}$ & $155=175-20^{1}$ & - & $4^{3}$ & - \\
\hline [83] & numerical & solar radiation & minichannel & $\begin{array}{l}1 \times \text { Eur. Therm. } \\
\text { GM200-71-14-16 }\end{array}$ & $176=199-23$ & 3.87 & $0.724=0.724-0.00074$ & $0.10 \%$ \\
\hline [84] & experimental & hot fluid & microchannel & $1 / 2 \times \mathrm{Bi}_{2} \mathrm{Te}_{3} \mu \mathrm{TEG}$ & 60 & - & $0.02=0.02-0.0015^{3}$ & $7.50 \%$ \\
\hline [85] & numerical & hot surface & microchannel & $1 \times$ Poly-Si $\mu$ TEG & $50=27-(-23)$ & 0.0009 & $\begin{aligned} 46 \times 10^{-9} & =71 \times 10^{-9}-25 \\
& \times 10^{-9}\end{aligned}$ & $54.35 \%$ \\
\hline [93] & numerical & hot fluid & $\begin{array}{l}\text { macrochannel } \\
\text { w. rotated fins }\end{array}$ & $1 \times \mathrm{Bi}_{2} \mathrm{Te}_{3} \mathrm{TEG}$ & $80=100-20^{1}$ & $\begin{array}{l}- \\
-\end{array}$ & $\begin{array}{l}15 \\
20\end{array}$ & $\begin{array}{l}- \\
-\end{array}$ \\
\hline [94] & experimental & hot fluid & macroch. w. fins & $\begin{array}{c}100 \times \text { Marlow Ind } \\
\text { TG12-4 }\end{array}$ & $175=200-25^{1}$ & - & $2=2.275-0.275^{3}$ & $13.75 \%$ \\
\hline [97] & experimental & hot fluid & $\begin{array}{l}\text { macrochannel } \\
\text { w. metal foam }\end{array}$ & $2 \times$ TEP-1-142T300 & $165=188-23^{1}$ & $\begin{array}{c}3.85 \\
4.9 \\
\end{array}$ & $\begin{array}{c}3.85^{3} \\
4.9^{3}\end{array}$ & - \\
\hline [98] & experimental & hot fluid & $\begin{array}{l}\text { macro channel } \\
\text { w. punched pan. }\end{array}$ & $40 \times \mathrm{Bi}_{2} \mathrm{Te}_{3}$ & $70.6^{1}$ & $\begin{array}{l}0.90 \\
1.22\end{array}$ & $\begin{array}{l}0.87=0.9-0.03 \\
0.98=1.1-0.12\end{array}$ & $\begin{array}{r}3.45 \% \\
12.24 \%\end{array}$ \\
\hline
\end{tabular}

${ }^{1}$ Temperatures difference not at the TEG surface. ${ }^{2}$ The power needed to cool down the cooling water included. ${ }^{3}$ The power to transport the hot fluid is included 


\section{Conclusions}

The review shows that active cooling using water (liquid) as the cooling medium offers the best potential to achieve a high net output power, compared to passive cooling and/or cooling by air. At the same time, it is observed that a careful optimization of the system is necessary to take the full advantage of active water-cooling. Depending on the goal of application, different system parameters may play a role in achieving the optimal solution. Therefore, the use of automatic multi-objective optimization procedures is encouraged.

Author Contributions: Conceptualization, B.P., A.C.B. and F.J.; methodology, B.P.; formal analysis, B.P.; investigation, B.P.; resources, B.P.; data curation, B.P.; writing-original draft preparation, B.P. and A.C.B.; writing-review and editing, B.P., A.C.B. and F.J.; visualization, B.P.; supervision, A.C.B. and F.J.; project administration, B.P., A.C.B. and F.J. All authors have read and agreed to the published version of the manuscript.

Funding: This research received no external funding.

Institutional Review Board Statement: Not applicable.

Informed Consent Statement: Not applicable.

Acknowledgments: The authors gratefully acknowledge the financial support of the Düsseldorf University of Applied Sciences through the PhD Support Program.

Conflicts of Interest: The authors declare no conflict of interest.

\section{Nomenclature}

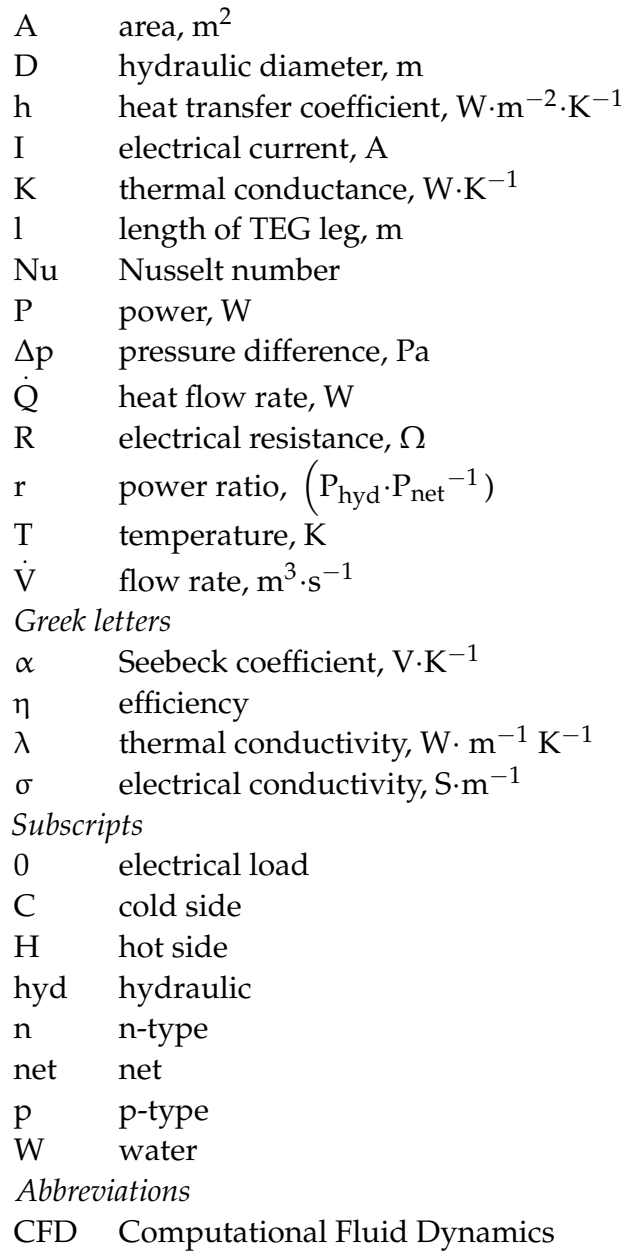


CHP Combined Heat and Power system

CPU Central Processing Unit

ORC Organic Rankine Cycle

TEC Thermoelectric Cooler

TEG Thermoelectric Generator

USB Universal Serial Bus

\section{References}

1. Rowe, D.M. CRC Handbook of Thermoelectrics; CRC Press: Boca Raton, FL, USA, 1995; ISBN 978-0-8493-0146-9.

2. He, W.; Zhang, G.; Zhang, X.; Ji, J.; Li, G.; Zhao, X. Recent Development and Application of Thermoelectric Generator and Cooler. Appl. Energy 2015, 143, 1-25. [CrossRef]

3. Elghool, A.; Basrawi, F.; Ibrahim, T.K.; Habib, K.; Ibrahim, H.; Idris, D.M.N.D. A Review on Heat Sink for Thermo-Electric Power Generation: Classifications and Parameters Affecting Performance. Energy Convers. Manag. 2017, 134, 260-277. [CrossRef]

4. Twaha, S.; Zhu, J.; Yan, Y.; Li, B. A Comprehensive Review of Thermoelectric Technology: Materials, Applications, Modelling and Performance Improvement. Renew. Sustain. Energy Rev. 2016, 65, 698-726. [CrossRef]

5. Champier, D. Thermoelectric Generators: A Review of Applications. Energy Convers. Manag. 2017, 140, 167-181. [CrossRef]

6. Deasy, M.J.; Baudin, N.; O'Shaughnessy, S.M.; Robinson, A.J. Simulation-Driven Design of a Passive Liquid Cooling System for a Thermoelectric Generator. Appl. Energy 2017, 205, 499-510. [CrossRef]

7. Shi, Y.; Wang, Y.; Mei, D.; Chen, Z. Wearable Thermoelectric Generator with Copper Foam as the Heat Sink for Body Heat Harvesting. IEEE Access 2018, 6, 43602-43611. [CrossRef]

8. El-Adl, A.S.; Mousa, M.G.; Hegazi, A.A. Performance Analysis of a Passively Cooled Thermoelectric Generator. Energy Convers. Manag. 2018, 173, 399-411. [CrossRef]

9. Gu, J.; Han, D.; Liu, Y.; Li, Y.; Jin, C.; Yu, W. Performance Analysis of a Thermoelectric Generator with Closed and Flooded Passive Cooling in Small-Scale Space. Energy Sustain. Dev. 2019, 51, 21-31. [CrossRef]

10. Boccardi, S.; Ciampa, F.; Meo, M. Design and Development of a Heatsink for Thermo-Electric Power Harvesting in Aerospace Applications. Smart Mater. Struct. 2019, 28, 105057. [CrossRef]

11. Jalil, S.A.; ElKabbash, M.; Li, Z.; Zhang, J.; Singh, S.; Zhan, Z.; Guo, C. Multipronged Heat-Exchanger Based on Femtosecond Laser-Nano/Microstructured Aluminum for Thermoelectric Heat Scavengers. Nano Energy 2020, 75, 104987. [CrossRef]

12. Alghoul, M.A.; Shahahmadi, S.A.; Yeganeh, B.; Asim, N.; Elbreki, A.M.; Sopian, K.; Tiong, S.K.; Amin, N. A Review of Thermoelectric Power Generation Systems: Roles of Existing Test Rigs/Prototypes and Their Associated Cooling Units on Output Performance. Energy Convers. Manag. 2018, 174, 138-156. [CrossRef]

13. Kumar, P.M.; Jagadeesh Babu, V.; Subramanian, A.; Bandla, A.; Thakor, N.; Ramakrishna, S.; Wei, H. The Design of a Thermoelectric Generator and Its Medical Applications. Designs 2019, 3, 22. [CrossRef]

14. Karthick, K.; Suresh, S.; Hussain, M.M.M.D.; Ali, H.M.; Kumar, C.S.S. Evaluation of Solar Thermal System Configurations for Thermoelectric Generator Applications: A Critical Review. Sol. Energy 2019, 188, 111-142. [CrossRef]

15. Hashim, H.T.; Rashid, F.L.; Kadham, M.J. Concentration Solar Thermoelectric Generator (CSTEG): Review Paper. JMERD 2021, $44,435-447$.

16. Ding, L.C.; Akbarzadeh, A.; Tan, L. A Review of Power Generation with Thermoelectric System and Its Alternative with Solar Ponds. Renew. Sustain. Energy Rev. 2018, 81, 799-812. [CrossRef]

17. Saleh, U.A.; Johar, M.A.; Jumaat, S.A.B.; Rejab, M.N.; Wan Jamaludin, W.A. Evaluation of a PV-TEG Hybrid System Configuration for an Improved Energy Output: A Review. IJRED 2021, 10, 385-400. [CrossRef]

18. Ma, T.; Qu, Z.; Yu, X.; Lu, X.; Wang, Q. A Review on Thermoelectric-Hydraulic Performance and Heat Transfer Enhancement Technologies of Thermoelectric Power Generator System. Therm. Sci. 2018, 22, 1885-1903. [CrossRef]

19. Patil, D.S.; Arakerimath, R.R.; Walke, P.V. Thermoelectric Materials and Heat Exchangers for Power Generation-A Review. Renew. Sustain. Energy Rev. 2018, 95, 1-22. [CrossRef]

20. Sajid, M.; Hassan, I.; Rahman, A. An Overview of Cooling of Thermoelectric Devices. Renew. Sustain. Energy Rev. 2017, 78, 15-22. [CrossRef]

21. Angrist, S.W. Direct Energy Conversion. In Allyn and Bacon Series in Mechanical Engineering and Applied Mechanics, 3rd ed.; Allyn and Bacon: Boston, MA, USA, 1976; ISBN 978-0-205-05581-4.

22. Favarel, C.; Bédécarrats, J.-P.; Kousksou, T.; Champier, D. Experimental Analysis with Numerical Comparison for Different Thermoelectric Generators Configurations. Energy Convers. Manag. 2016, 107, 114-122. [CrossRef]

23. Lu, X.; Yu, X.; Qu, Z.; Wang, Q.; Ma, T. Experimental Investigation on Thermoelectric Generator with Non-Uniform Hot-Side Heat Exchanger for Waste Heat Recovery. Energy Convers. Manag. 2017, 150, 403-414. [CrossRef]

24. Esarte, J.; Min, G.; Rowe, D.M. Modelling Heat Exchangers for Thermoelectric Generators. J. Power Sources 2001, 93 , 72-76. [CrossRef]

25. Lesage, F.J.; Pagé-Potvin, N. Experimental Analysis of Peak Power Output of a Thermoelectric Liquid-to-Liquid Generator under an Increasing Electrical Load Resistance. Energy Convers. Manag. 2013, 66, 98-105. [CrossRef]

26. Gould, C.A.; Shammas, N.Y.A.; Grainger, S.; Taylor, I. Thermoelectric Cooling of Microelectronic Circuits and Waste Heat Electrical Power Generation in a Desktop Personal Computer. Mater. Sci. Eng. B 2011, 176, 316-325. [CrossRef] 
27. Li, Y.H.; Wu, Z.H.; Xie, H.Q.; Xing, J.J.; Mao, J.H.; Wang, Y.Y.; Li, Z. An Experimental Investigation of a Thermoelectric Power Generation System with Different Cold-Side Heat Dissipation. IOP Conf. Ser. Mater. Sci. Eng. 2018, 292, 012063. [CrossRef]

28. Patil, D.S.; Arakerimath, R.R.; Walke, P.V. Experimental Investigation and Optimization of a Low-Temperature Thermoelectric Module with Different Operating Conditions. WJE 2019, 16, 368-376. [CrossRef]

29. Kumar, R.; Sonthalia, A.; Goel, R. Experimental Study on Waste Heat Recovery from an IC Engine Using Thermoelectric Technology. Therm. Sci. 2011, 15, 1011-1022. [CrossRef]

30. Favarel, C.; Bédécarrats, J.-P.; Kousksou, T.; Champier, D. Numerical Optimization of the Occupancy Rate of Thermoelectric Generators to Produce the Highest Electrical Power. Energy 2014, 68, 104-116. [CrossRef]

31. Lu, C.; Wang, S.; Chen, C.; Li, Y. Effects of Heat Enhancement for Exhaust Heat Exchanger on the Performance of Thermoelectric Generator. Appl. Therm. Eng. 2015, 89, 270-279. [CrossRef]

32. Zhang, Y.; Cleary, M.; Wang, X.; Kempf, N.; Schoensee, L.; Yang, J.; Joshi, G.; Meda, L. High-Temperature and High-Power-Density Nanostructured Thermoelectric Generator for Automotive Waste Heat Recovery. Energy Convers. Manag. 2015, 105, 946-950. [CrossRef]

33. Heghmanns, A.; Wilbrecht, S.; Beitelschmidt, M.; Geradts, K. Parameter Optimization and Operating Strategy of a TEG System for Railway Vehicles. J. Electron. Mater. 2016, 45, 1633-1641. [CrossRef]

34. Liu, C.; Deng, Y.D.; Wang, X.Y.; Liu, X.; Wang, Y.P.; Su, C.Q. Multi-Objective Optimization of Heat Exchanger in an Automotive Exhaust Thermoelectric Generator. Appl. Therm. Eng. 2016, 108, 916-926. [CrossRef]

35. Wang, Y.; Li, S.; Zhang, Y.; Yang, X.; Deng, Y.; Su, C. The Influence of Inner Topology of Exhaust Heat Exchanger and Thermoelectric Module Distribution on the Performance of Automotive Thermoelectric Generator. Energy Convers. Manag. 2016, 126, 266-277. [CrossRef]

36. Gaurav, K.; Sisodia, S.; Pandey, S.K. Calculation of Efficiency and Power Output by Considering Different Realistic Prospects for Recovering Heat from Automobile Using Thermoelectric Generator. J. Renew. Sustain. Energy 2017, 9, 064703. [CrossRef]

37. Lan, S.; Rouaud, C.; Stobart, R.; Chen, R.; Yang, Z.; Zhao, D. The Potential of Thermoelectric Generator in Parallel Hybrid Vehicle Applications; SAE Technical Paper 2017-01-0189; SAE International: Warrendale, PA, USA, 2017. [CrossRef]

38. Huang, K.; Yan, Y.; Li, B.; Li, Y.; Li, K.; Li, J. A Novel Design of Thermoelectric Generator for Automotive Waste Heat Recovery. Automot. Innov. 2018, 1, 54-61. [CrossRef]

39. Lu, X.; Yu, X.; Wang, Q.; Chen, Y.; Ma, T. Numerical Study on Nonuniform Segmented Enhancement Method for Thermoelectric Power Generator. Numer. Heat Transf. Part A Appl. 2019, 76, 605-627. [CrossRef]

40. Quan, R.; Li, T.; Yue, Y.; Chang, Y.; Tan, B. Experimental Study on a Thermoelectric Generator for Industrial Waste Heat Recovery Based on a Hexagonal Heat Exchanger. Energies 2020, 13, 3137. [CrossRef]

41. Zhu, J.; Gao, J.; Chen, M.; Zhang, J.; Du, Q.; Rosendahl, L.A.; Suzuki, R.O. Experimental Study of a Thermoelectric Generation System. J. Electron. Mater. 2011, 40, 744-752. [CrossRef]

42. Yedala, N.; Kaisare, N.S. Modeling of Thermal Integration of a Catalytic Microcombustor with a Thermoelectric for Power Generation Applications. Energy Fuels 2021, 35, 5141-5152. [CrossRef]

43. Champier, D.; Bédécarrats, J.P.; Kousksou, T.; Rivaletto, M.; Strub, F.; Pignolet, P. Study of a TE (Thermoelectric) Generator Incorporated in a Multifunction Wood Stove. Energy 2011, 36, 1518-1526. [CrossRef]

44. Suter, C.; Jovanovic, Z.R.; Steinfeld, A. A 1 kWe Thermoelectric Stack for Geothermal Power Generation-Modeling and Geometrical Optimization. Appl. Energy 2012, 99, 379-385. [CrossRef]

45. He, W.; Su, Y.; Riffat, S.B.; Hou, J.; Ji, J. Parametrical Analysis of the Design and Performance of a Solar Heat Pipe Thermoelectric Generator Unit. Appl. Energy 2011, 88, 5083-5089. [CrossRef]

46. Zheng, X.F.; Liu, C.X.; Boukhanouf, R.; Yan, Y.Y.; Li, W.Z. Experimental Study of a Domestic Thermoelectric Cogeneration System. Appl. Therm. Eng. 2014, 62, 69-79. [CrossRef]

47. Ohara, B.; Wagner, M.; Kunkle, C.; Watson, P.; Williams, R.; Donohoe, R.; Ugarte, K.; Wilmoth, R.; Chong, M.Z.; Lee, H. Residential Solar Combined Heat and Power Generation Using Solar Thermoelectric Generation. J. Electron. Mater. 2015, 44, $2132-2141$. [CrossRef]

48. Atta, R.M. Solar Thermoelectric Cooling Using Closed Loop Heat Exchangers with Macro Channels. Heat Mass Transf. 2017, 53, 2241-2254. [CrossRef]

49. Su, C.Q.; Zhu, D.C.; Deng, Y.D.; Wang, Y.P.; Liu, X. Effect of Cooling Units on the Performance of an Automotive Exhaust-Based Thermoelectric Generator. J. Electron. Mater. 2017, 46, 2822-2831. [CrossRef]

50. Su, C.Q.; Xu, M.; Wang, W.S.; Deng, Y.D.; Liu, X.; Tang, Z.B. Optimization of Cooling Unit Design for Automotive Exhaust-Based Thermoelectric Generators. J. Electron. Mater. 2015, 44, 1876-1883. [CrossRef]

51. Chen, J.; Li, K.; Liu, C.; Li, M.; Lv, Y.; Jia, L.; Jiang, S. Enhanced Efficiency of Thermoelectric Generator by Optimizing Mechanical and Electrical Structures. Energies 2017, 10, 1329. [CrossRef]

52. Zhou, S.; Sammakia, B.G.; White, B.; Borgesen, P. Multiscale Modeling of Thermoelectric Generators for the Optimized Conversion Performance. Int. J. Heat Mass Transf. 2013, 62, 435-444. [CrossRef]

53. Niu, X.; Yu, J.; Wang, S. Experimental Study on Low-Temperature Waste Heat Thermoelectric Generator. J. Power Sources 2009, 188, 621-626. [CrossRef]

54. Yu, J.; Zhao, H. A Numerical Model for Thermoelectric Generator with the Parallel-Plate Heat Exchanger. J. Power Sources 2007, 172, 428-434. [CrossRef] 
55. Chen, W.-H.; Liao, C.-Y.; Hung, C.-I.; Huang, W.-L. Experimental Study on Thermoelectric Modules for Power Generation at Various Operating Conditions. Energy 2012, 45, 874-881. [CrossRef]

56. Lv, S.; He, W.; Jiang, Q.; Hu, Z.; Liu, X.; Chen, H.; Liu, M. Study of Different Heat Exchange Technologies Influence on the Performance of Thermoelectric Generators. Energy Convers. Manag. 2018, 156, 167-177. [CrossRef]

57. Karri, M.A.; Thacher, E.F.; Helenbrook, B.T. Exhaust Energy Conversion by Thermoelectric Generator: Two Case Studies. Energy Convers. Manag. 2011, 52, 1596-1611. [CrossRef]

58. Lei, X.; Wang, Y.; Deng, Y.; Su, C.; Liu, X.; Chen, G. Combined Numerical and Experimental Investigation on the Optimum Coolant Flow Rate for Automotive Thermoelectric Generators. J. Electron. Mater. 2019, 48, 1981-1990. [CrossRef]

59. Bakar, R.A.; Singh, B.; Remeli, M.F.; Seng, O.K. Experimental Electrical Characterisation of Thermoelectric Generator Using Forced Convection Water Cooling. JMECHE 2020, 17, 1-16.

60. Zhang, T. Design and Optimization Considerations for Thermoelectric Devices. Energy Convers. Manag. 2016, 112, 404-412. [CrossRef]

61. Deng, Y.D.; Liu, X.; Chen, S.; Xing, H.B.; Su, C.Q. Research on the Compatibility of the Cooling Unit in an Automotive Exhaust-Based Thermoelectric Generator and Engine Cooling System. J. Electron. Mater. 2014, 43, 1815-1823. [CrossRef]

62. Du, Q.; Diao, H.; Niu, Z.; Zhang, G.; Shu, G.; Jiao, K. Effect of Cooling Design on the Characteristics and Performance of Thermoelectric Generator Used for Internal Combustion Engine. Energy Convers. Manag. 2015, 101, 9-18. [CrossRef]

63. Aranguren, P.; Astrain, D.; Martínez, A. Study of Complete Thermoelectric Generator Behavior Including Water-to-Ambient Heat Dissipation on the Cold Side. J. Electron. Mater. 2014, 43, 2320-2330. [CrossRef]

64. Aranguren, P.; Astrain, D.; Pérez, M.G. Computational and Experimental Study of a Complete Heat Dissipation System Using Water as Heat Carrier Placed on a Thermoelectric Generator. Energy 2014, 74, 346-358. [CrossRef]

65. Aranguren, P.; Astrain, D.; Rodríguez, A.; Martínez, A. Experimental Investigation of the Applicability of a Thermoelectric Generator to Recover Waste Heat from a Combustion Chamber. Appl. Energy 2015, 152, 121-130. [CrossRef]

66. Aranguren, P.; Astrain, D.; Rodríguez, A.; Martínez, A. Net Thermoelectric Power Generation Improvement through Heat Transfer Optimization. Appl. Therm. Eng. 2017, 120, 496-505. [CrossRef]

67. Aranguren, P.; Araiz, M.; Astrain, D. Auxiliary Consumption: A Necessary Energy That Affects Thermoelectric Generation. Appl. Therm. Eng. 2018, 141, 990-999. [CrossRef]

68. Montecucco, A.; Siviter, J.; Knox, A.R. Combined Heat and Power System for Stoves with Thermoelectric Generators. Appl. Energy 2017, 185, 1336-1342. [CrossRef]

69. Aravind, B.; Raghuram, G.K.S.; Kishore, V.R.; Kumar, S. Compact Design of Planar Stepped Micro Combustor for Portable Thermoelectric Power Generation. Energy Convers. Manag. 2018, 156, 224-234. [CrossRef]

70. Aravind, B.; Saini, D.K.; Kumar, S. Experimental Investigations on the Role of Various Heat Sinks in Developing an Efficient Combustion Based Micro Power Generator. Appl. Therm. Eng. 2019, 148, 22-32. [CrossRef]

71. Aravind, B.; Khandelwal, B.; Ramakrishna, P.A.; Kumar, S. Towards the Development of a High Power Density, High Efficiency, Micro Power Generator. Appl. Energy 2020, 261, 114386. [CrossRef]

72. Aravind, B.; Hiranandani, K.; Kumar, S. Experimental and Numerical Studies on Combustion-Based Small-Scale Power Generators. In Sustainable Development for Energy, Power, and Propulsion; De, A., Gupta, A.K., Aggarwal, S.K., Kushari, A., Runchal, A.K., Eds.; Green Energy and Technology; Springer: Singapore, 2021; pp. 221-247. ISBN 9789811556661.

73. Kandlikar, S.G.; Grande, W.J. Evolution of Microchannel Flow Passages-Thermohydraulic Performance and Fabrication Technology. Heat Transf. Eng. 2003, 24, 3-17. [CrossRef]

74. Rezania, A.; Rosendahl, L.A. Evaluating Thermoelectric Power Generation Device Performance Using a Rectangular Microchannel Heat Sink. J. Electron. Mater. 2011, 40, 481-488. [CrossRef]

75. Rezania, A.; Rosendahl, L.A. Thermal Effect of a Thermoelectric Generator on Parallel Microchannel Heat Sink. Energy 2012, 37, 220-227. [CrossRef]

76. Rezania, A.; Rosendahl, L.A. New Configurations of Micro Plate-Fin Heat Sink to Reduce Coolant Pumping Power. J. Electron. Mater. 2012, 41, 1298-1304. [CrossRef]

77. Rezania, A.; Rosendahl, L.A.; Andreasen, S.J. Experimental Investigation of Thermoelectric Power Generation versus Coolant Pumping Power in a Microchannel Heat Sink. Int. Commun. Heat Mass Transf. 2012, 39, 1054-1058. [CrossRef]

78. Rezania, A.; Yazawa, K.; Rosendahl, L.A.; Shakouri, A. Co-Optimized Design of Microchannel Heat Exchangers and Thermoelectric Generators. Int. J. Therm. Sci. 2013, 72, 73-81. [CrossRef]

79. Rezania, A.; Rosendahl, L.A. A Comparison of Micro-Structured Flat-Plate and Cross-Cut Heat Sinks for Thermoelectric Generation Application. Energy Convers. Manag. 2015, 101, 730-737. [CrossRef]

80. Kiflemariam, R.; Lin, C.-X. Numerical Simulation of Integrated Liquid Cooling and Thermoelectric Generation for Self-Cooling of Electronic Devices. Int. J. Therm. Sci. 2015, 94, 193-203. [CrossRef]

81. Abdo, A.; Saito, T.; Ookawara, S.; Radwan, A.; Ahmed, M. Experimental Study of the Performance of Concentrator Photovoltaic/Thermoelectric Generator System Integrated with a New 3D Printed Microchannel Heat Sink. Int. J. Energy Res. 2021, 45, 7741-7763. [CrossRef]

82. Lee, W.; Lee, J. Development of a Compact Thermoelectric Generator Consisting of Printed Circuit Heat Exchangers. Energy Convers. Manag. 2018, 171, 1302-1310. [CrossRef] 
83. Abd El-Samie, M.M.; Shedid, M.H.; Hassan, M.A.M. Numerical Study of a Solar Thermoelectric Generator with Nanofluids Based Microcooling System. Numer. Heat Transf. Part A Appl. 2018, 74, 1804-1826. [CrossRef]

84. Wojtas, N.; Grab, M.; Glatz, W.; Hierold, C. Stacked Micro Heat Exchange System for Optimized Thermal Coupling of MicroTEGs. J. Electron. Mater. 2013, 42, 2103-2109. [CrossRef]

85. En Heng, Y.; Abd Manaf, A.; Sing Lee, S. Design Optimization of a Microfluidic-Integrated Thermoelectric Power Generator. Smart Mater. Struct. 2014, 23, 085003. [CrossRef]

86. Suzuki, R.O.; Sasaki, Y.; Fujisaka, T.; Chen, M. Effects of Fluid Directions on Heat Exchange in Thermoelectric Generators. J. Electron. Mater. 2012, 41, 1766-1770. [CrossRef]

87. Pandit, J. Numerical and Experimental Design of High Performance Heat Exchanger System for A Thermoelectric Power Generator for Implementation in Automobile Exhaust Gas Waste Heat Recovery. Ph.D. dissertation, Virginia Tech, Blacksburg, VA, USA, 2014.

88. Pfeiffelmann, B.; Benim, A.C.; Joos, F. A Finite Volume Analysis of Thermoelectric Generators. Heat Transf. Eng. 2019, 40, 1442-1450. [CrossRef]

89. Pfeiffelmann, B.; Benim, A.C.; Joos, F. Computational Investigation of Impingement Cooling of Thermoelectric Generators. Heat Transf. Eng. 2021, 42, 282-295. [CrossRef]

90. Bhattacharyya, S.; Chattopadhyay, H.; Benim, A.C. Heat Transfer Enhancement of Laminar Flow of Ethylene Glycol through a Square Channel Fitted with Angular Cut Wavy Strip. Procedia Eng. 2016, 157, 19-28. [CrossRef]

91. Li, W.; Paul, M.C.; Siviter, J.; Montecucco, A.; Knox, A.R.; Sweet, T.; Min, G.; Baig, H.; Mallick, T.K.; Han, G.; et al. Thermal Performance of Two Heat Exchangers for Thermoelectric Generators. Case Stud. Therm. Eng. 2016, 8, 164-175. [CrossRef]

92. Chen, W.-H.; Wang, C.-C.; Hung, C.-I.; Yang, C.-C.; Juang, R.-C. Modeling and Simulation for the Design of Thermal-Concentrated Solar Thermoelectric Generator. Energy 2014, 64, 287-297. [CrossRef]

93. Qiang, J.W.; Yu, C.G.; Deng, Y.D.; Su, C.Q.; Wang, Y.P.; Yuan, X.H. Multi-Objective Optimization Design for Cooling Unit of Automotive Exhaust-Based Thermoelectric Generators. J. Electron. Mater. 2016, 45, 1679-1688. [CrossRef]

94. Zhou, S.; Sammakia, B.G.; White, B.; Borgesen, P.; Chen, C. Multiscale Modeling of Thermoelectric Generators for Conversion Performance Enhancement. Int. J. Heat Mass Transf. 2015, 81, 639-645. [CrossRef]

95. Bjørk, R.; Sarhadi, A.; Pryds, N.; Lindeburg, N.; Viereck, P. A Thermoelectric Power Generating Heat Exchanger: Part I—Experimental Realization. Energy Convers. Manag. 2016, 119, 473-480. [CrossRef]

96. Sarhadi, A.; Bjørk, R.; Lindeburg, N.; Viereck, P.; Pryds, N. A Thermoelectric Power Generating Heat Exchanger: Part II—Numerical Modeling and Optimization. Energy Convers. Manag. 2016, 119, 481-487. [CrossRef]

97. Zhu, D.C.; Su, C.Q.; Deng, Y.D.; Wang, Y.P.; Liu, X. The Influence of the Inner Topology of Cooling Units on the Performance of Automotive Exhaust-Based Thermoelectric Generators. J. Electron. Mater. 2018, 47, 3320-3329. [CrossRef]

98. Wang, T.; Liu, T.; Luan, W.; Tu, S.-T.; Yan, J. Performance Improvement of High-Temperature Silicone Oil Based Thermoelectric Generator. Energy Procedia 2017, 105, 1211-1218. [CrossRef]

99. Amaral, C.; Brandão, C.; Sempels, É.V.; Lesage, F.J. Net Thermoelectric Generator Power Output Using Inner Channel Geometries with Alternating Flow Impeding Panels. Appl. Therm. Eng. 2014, 65, 94-101. [CrossRef]

100. Amaral, C.; Brandão, C.; Sempels, É.V.; Lesage, F.J. Thermoelectric Power Enhancement by Way of Flow Impedance for Fixed Thermal Input Conditions. J. Power Sources 2014, 272, 672-680. [CrossRef]

101. Sempels, E.V.; Lesage, F.J. Optimal Thermal Conditions for Maximum Power Generation When Operating Thermoelectric Liquid-to-Liquid Generators. IEEE Trans. Compon. Packag. Manufact. Technol. 2017, 7, 872-881. [CrossRef] 